\title{
Stellar evolution through the ages: period variations in galactic RRab stars as derived from the GEOS database and TAROT telescopes *
}

\author{
J. F. Le Borgne ${ }^{1,2}$, A. Paschke ${ }^{1,3}$, J. Vandenbroere ${ }^{1}$, E. Poretti ${ }^{1,4}$, A. Klotz ${ }^{5}$, M. Boër ${ }^{6}$, Y. Damerdji6,7, \\ M. Martignoni ${ }^{1,3}$, and F. Acerbi ${ }^{1}$
}

${ }^{1}$ GEOS (Groupe Européen d'Observations Stellaires), 23 Parc de Levesville, 28300 Bailleau l'Evêque, France e-mail: leborgne@ast.obs-mip.fr

2 Laboratoire d'Astrophysique de Toulouse-Tarbes, Observatoire Midi-Pyrénées (CNRS/UPS), Toulouse, France

Bundesdeutsche Arbeitsgemeinschaft für Veränderliche Sterne e.V. (BAV), Munsterdamm 90, 12169 Berlin, Germany

4 INAF-Osservatorio Astronomico di Brera, via E. Bianchi 46, 23807 Merate, Italy

5 Centre d'Étude Spatiale des Rayonnements, Observatoire Midi-Pyrénées (CNRS/UPS), Toulouse, France

6 Observatoire de Haute-Provence (CNRS/OAMP), France

7 Institut d'Astrophysique et de Géophysique de l'Université de Liège, Allée du 6 Août 17, 4000 Liège, Belgium

Received 28 May 2007 / Accepted 18 September 2007

\begin{abstract}
Context. The theory of stellar evolution can be more closely tested if we have the opportunity to measure new quantities. Nowadays, observations of galactic RR Lyr stars are available on a time baseline exceeding 100 years. Therefore, we can exploit the possibility of investigating period changes, continuing the pioneering work started by V. P. Tsesevich in 1969.

Aims. We collected the available times of maximum brightness of the galactic RR Lyr stars in the GEOS RR Lyr database. Moreover, we also started new observational projects, including surveys with automated telescopes, to characterise the O-C diagrams better. Methods. The database we built has proved to be a very powerful tool for tracing the period variations through the ages. We analyzed 123 stars showing a clear O-C pattern (constant, parabolic or erratic) by means of different least-squares methods.

Results. Clear evidence of period increases or decreases at constant rates has been found, suggesting evolutionary effects. The median values are $\beta=+0.14 \mathrm{~d} \mathrm{Myr}^{-1}$ for the 27 stars showing a period increase and $\beta=-0.20 \mathrm{~d} \mathrm{Myr}^{-1}$ for the 21 stars showing a period decrease. The large number of RR Lyr stars showing a period decrease (i.e., blueward evolution) is a new and intriguing result. There is an excess of RR Lyr stars showing large, positive $\beta$ values. Moreover, the observed $\beta$ values are slightly larger than those predicted by theoretical models.
\end{abstract}

Key words. astronomical data bases: miscellaneous - stars: evolution - stars: horizontal-branch - stars: variables: RR Lyr

\section{Introduction}

RR Lyr variables are low-mass stars in a core helium burning phase; they fill the part of the HR diagram where the horizontal branch intersects the classical instability strip. The crossing of the instability strip can take place in both directions; as a consequence, the periods will be either increasing, if the stars evolve from blue to red, or decreasing, if they evolve from red to blue. Despite its importance as a test for the stellar evolution theory, the observed rate of the period changes is still an unknown quantity. It has been measured in globular clusters (e.g., Smith \& Sandage 1981; Lee 1991; Jurcsik et al. 2001), comparing periods determined in different epochs. However, this task has not been undertaken yet on the wide population of galactic RR Lyr stars, though most of them have been studied for tens of years, several of them since the end of the XIXth century, and therefore the available data are almost continuous. One of the critical points is to determine the importance of the negative rates, i.e., the

$\star$ Tables 3, 4, 5 and Figs. 2, 3 are only available in electronic form at http://www . aanda. org period decreases. Such rates have been observed in some cluster stars (Jurcsik et al. 2001), but it is unclear in which evolutionary phase they occur (Sweigart \& Renzini 1979).

In the present paper, we derive the period variation rate of the best observed RR Lyr stars belonging to the RRab subclass. For this purpose we use the GEOS RR Lyr database which is described in Sect. 2. The observations of the TAROT telescopes coordinated in the GEOS RR Lyr Survey give a strong impulse to this analysis, providing a large number of times of maximum brightness in the recent years. They complete the effort of the amateur observers, in particular in the European associations BAV (Bundesdeutsche Arbeitsgemeinschaft für Veränderliche Sterne) and GEOS (Groupe Européen d'Observations Stellaires), which have been surveying these stars for years. These new observations are described in Sect. 2.2. Next, Sect. 3 shows how the data were analysed. In Sect. 4, we analyse the stars with constant period variation. Section 5 is devoted to the study of some particularities encountered during the present work: Blazhko and light-time 
effects. Finally, a discussion of the results is developed in Sect. 6 in the light of stellar evolution.

\section{The GEOS RR Lyr database and survey: a V. P. Tsesevich's heritage}

In his book "RR Lyrae stars", V. P. Tsesevich (1969) made a summary of the period variation behavior of RR Lyr stars from the observations made during the 60 years or so after the discovery of these stars. Nowadays, 40 more years have elapsed, allowing 100 years of data for some stars. It is timely to investigate what the data accumulated since Tsesevich's work bring to the understanding of the period variation of RR Lyr stars and of the stellar evolution of horizontal branch stars.

\subsection{The GEOS RR Lyr Database}

To complete Tsesevich's data collection, the amateur/ professional association GEOS has built a database aiming to put together all possible RR Lyr light maximum times published in the literature. The publications from the end of the XIX $^{\text {th }}$ century up to today were scanned for this purpose. The database continues to be fed by recent observations from amateur astronomers of the European groups GEOS and BAV. To date, the database ${ }^{1}$ contains about 50000 maximum times from more than 3000 RR Lyr stars.

The stars concerned are galactic RRab and RRc. The collected times of light maxima were obtained from observations using various techniques, either visually, with electronic devices, or photographically, and by hundreds of observers. This heterogeneity is taken into account in the analysis of the $\mathrm{O}-\mathrm{C}$ diagrams which are the basis of the present paper. The $\mathrm{O}-\mathrm{C}$ diagrams are obtained plotting the differences between the observed and calculated times of maximum brightness (i.e., the $\mathrm{O}-\mathrm{C}$ values) vs. the elapsed cycles. Multicolor photometry of RR Lyr stars (e.g., the extensive $U B V$ light curves obtained by Oláh \& Szeidl 1978 and Szeidl et al. 1986) shows that the colour effects on the determination of the times of maximum brightness are negligible with respect to the period variations we are searching for, since they are much smaller than the errors on the determinations themselves. It is also obvious that the precision of modern observations, either with photoelectric detectors or CCDs, is much better than visual and photographic observations. However, the uncertainties of the visual and photographic determinations are much less than the $\mathrm{O}-\mathrm{C}$ variations we are studying. A particularity of photographic observations is that the corresponding published maximum is often not the result of the analysis of a lightcurve obtained during one night, but rather one single "bright" point. These observations were useful at the time when people searched for the pulsation period of the star, but unavoidably this method introduces an additional scatter in the $\mathrm{O}-\mathrm{C}$ diagrams.

\subsection{The TAROT Telescopes}

The telescopes TAROT (Télescope à Action Rapide pour les Objets Transitoires = Rapid Action Telescope for Transient Objects; Bringer et al. 1999) are automatic, autonomous observatories composed of $25-\mathrm{cm}$ telescopes whose first objective is the real-time detection of the optical transient counterparts

1 The GEOS database is freely accessible on the internet at the address http://dbrr.ast.obs-mip.fr/. This site is hosted by the Laboratoire d'Astrophysique de Toulouse-Tarbes, Observatoire MidiPyrénées, Toulouse, France of GRBs in the visible (Klotz et al. 2006) ${ }^{2}$. One of these telescopes is located in the northern hemisphere at Calern Observatory (Observatoire de la Côte d'Azur, University of Nice, France), and the second one is in the southern hemisphere at ESO, La Silla, Chile. The telescopes have a field of view of $1.86 \times 1.86 \mathrm{deg}^{2}$. During operation no human action is necessary, neither for calibration and science frames nor for data processing. The roof of the buildings are retractable to allow rapid movement to any direction in the sky. TAROT telescopes are able to point in any direction in less than $5 \mathrm{~s}$ (including CCD operations and filter movements). They can detect stars of magnitude $V=16.2$ in $10 \mathrm{~s}$ exposure time, or $V=18.2$ in $60 \mathrm{~s}$. TAROTs are able to monitor a GRB $8 \mathrm{sec}$ after being triggered, about $20 \mathrm{~s}$ after the gamma ray detection (Boër et al. 2001).

A dedicated software program optimises the process: it is able to decide at any time what is the best observation to do next, given program objects, priorities, alerts and constraints from the astronomer such as measurement frequency (Bringer et al. 1999). Weather stations are linked to the TAROT computers. If it rains or if the temperature reaches the dew temperature or the humidity becomes higher than $90 \%$, the roof remains closed. The system performs an automatic data reduction (dark and flat corrections, astrometric and photometric calibrations) in real time (see Damerdji et al. 2007). In the case of the images dedicated to the RR Lyr survey, a catalogue of the measurements is updated after each observation and is available on the web about 2 min after the image has been taken.

\subsection{The GEOS RR Lyr survey with TAROT telescopes}

In addition to the detection and localisation of GRBs, TAROTs follow the CNES artificial satellites, and a fraction of the observing time is left to other astronomical programs. Therefore, the efforts made by hundreds of observers over one century to monitor the maximum times of RR Lyr stars may be continued nowadays by much more efficient techniques, thanks to the use of these small robotic telescopes. Indeed, the authors started a monitoring of maxima of RRab stars, called GEOS RR Lyr survey, on 2004 January 29 using the northern TAROT and in September 2006 using the southern one. The capabilities of the system and the time-sharing allow us to schedule the observation of up to 6 maxima of RR Lyr stars per night and per telescope. The schedule is sent to the control sofware once per month. The aim is to obtain at least one maximum per star with $V<12.5$ (Calern observatory) or with $V<13.5$ (Chile) and per year, in order to check the period stability on time scales of decades. In practice, the number of maxima observed for each star of the programme is typically 5-10 per year. Only stars from the General Catalogue of Variable Stars (GCVS, Kholopov et al. 1988) have been observed so far: this catalogue contains stars which have often been observed for more than 50 years. In 3 years of operation, from January 2004 to December 2006, TAROT-Calern observed 1288 maxima on 130 stars; TAROT-Chile observed 556 maxima on 126 stars during the first 6 months of operation.

For each maximum, the telescopes obtain an average of 50 measurements in $4.8 \mathrm{~h}$. The number of frames having contributed to determine the maximum times is 98000 in three years. The times of maximum brightness are determined by fitting the data points by means of a cubic spline function with a non-zero smoothing parameter. The smoothing parameter was

2 TAROT telescopes were funded by the Centre National de la Recherche Scientifique (CNRS). The project is led by a team of French laboratories (CESR, LATT and OHP). 
Table 1. Number of RR Lyr stars per magnitude (at minimum) bin observed from 2004 to 2006.

\begin{tabular}{rrrrrr}
\hline $\begin{array}{c}\text { Magnitude } \\
\text { at minimum }\end{array}$ & \multicolumn{5}{c}{ Number of stars } \\
& in GCVS & $\begin{array}{c}\text { BAV+GEOS } \\
2002-2006\end{array}$ & $\begin{array}{c}\text { GEOS } \\
\text { 2004-2006 }\end{array}$ & $\begin{array}{c}\text { BAV } \\
\text { 2002-2005 }\end{array}$ \\
\hline $9.5-10.0$ & 1 & 1 & $100 \%$ & 1 & 1 \\
$10.0-10.5$ & 9 & 8 & $88 \%$ & 8 & 7 \\
$10.5-11.0$ & 9 & 9 & $100 \%$ & 9 & 8 \\
$11.0-11.5$ & 17 & 17 & $100 \%$ & 13 & 15 \\
$11.5-12.0$ & 23 & 21 & $91 \%$ & 19 & 17 \\
$12.0-12.5$ & 38 & 37 & $97 \%$ & 35 & 31 \\
$12.5-13.0$ & 38 & 29 & $76 \%$ & 21 & 22 \\
$13.0-13.5$ & 59 & 46 & $77 \%$ & 19 & 41 \\
$13.5-14.0$ & 69 & 34 & $49 \%$ & 4 & 33 \\
$14.0-14.5$ & 93 & 23 & $24 \%$ & 3 & 21 \\
$14.5-15.0$ & 108 & 24 & $22 \%$ & 2 & 22 \\
$15.0-15.5$ & 164 & 20 & $12 \%$ & 2 & 18 \\
$15.5-16.0$ & 188 & 13 & $6 \%$ & 3 & 10 \\
$16.0-16.5$ & 222 & 5 & $2 \%$ & 0 & 5 \\
$16.5-17.0$ & 187 & 2 & $1 \%$ & 0 & 2 \\
\hline
\end{tabular}

selected case-by-case, depending on the number of points and their scatter. The error bars are estimated from the data sampling. The nominal sampling is composed of two consecutive 30 -s exposures taken every $10 \mathrm{~min}$ in a time interval of $2 \mathrm{~h}$, centred around the predicted maximum time and 20 min outside this interval. The resulting mean separation between 2 measurements is $5.8 \mathrm{~min}$. However, the nominal sampling may be altered by local events (e.g., weather or telescope operation). For a well covered maximum, the mean error bar is about $0.003 \mathrm{~d}$ (4.3 min); usually, error bars range from 0.002 to $0.010 \mathrm{~d}$.

\subsection{Survey statistics}

In order to check the efficiency of the survey, we analysed the production of maximum times during the first three years of TAROT-Calern. The RR Lyr stars in the GCVS with $V>$ 9.0 (at minimum) and with $\delta>-10^{\circ}$ are sorted in bins of 0.5 mag width. RR Lyr itself is not considered, since this bright variable (7.06-8.12 V) is currently monitored with several techniques (visual, photographic, photoelectric and CCD photometry, medium and high resolution spectroscopy). Since the magnitudes at minimum come from the GCVS, the photometric systems are heterogeneous, but close to Johnson $V$ magnitudes. We also compare the statistics of the TAROT (GEOS) production (from 2004 to 2006) with those of the observers of BAV group (from 2002 to 2005). Both groups published their maximum times in the Information Bulletin on Variable Stars: see Le Borgne et al. (2004, 2005a,b, 2006a,b and 2007) for GEOS maxima, and Agerer \& Hübscher (2002, 2003), Hübscher (2005), Hübscher et al. $(2005,2006)$ for BAV maxima. BAV obtains this result using several telescopes operated by about 20 observers.

Table 1 and Fig. 1 illustrate the results of the statistical analysis. Indeed, the results show that the two groups put together have a completeness of $97 \%$ up to $V=12.5$ (magnitude at minimum); 93 of the 97 RRab stars listed in the GCVS have been observed. Individually, the GEOS and BAV surveys have a completeness of $88 \%$ and $81 \%$, respectively. We note that, for the GEOS survey with TAROT telescopes, $V=12.5$ is a natural limit for a $25-\mathrm{cm}$ telescope. Moreover, both surveys have a decrease in completeness beyond this magnitude imposed by the typical diameter of the telescopes (20-30 cm mirror diameter),

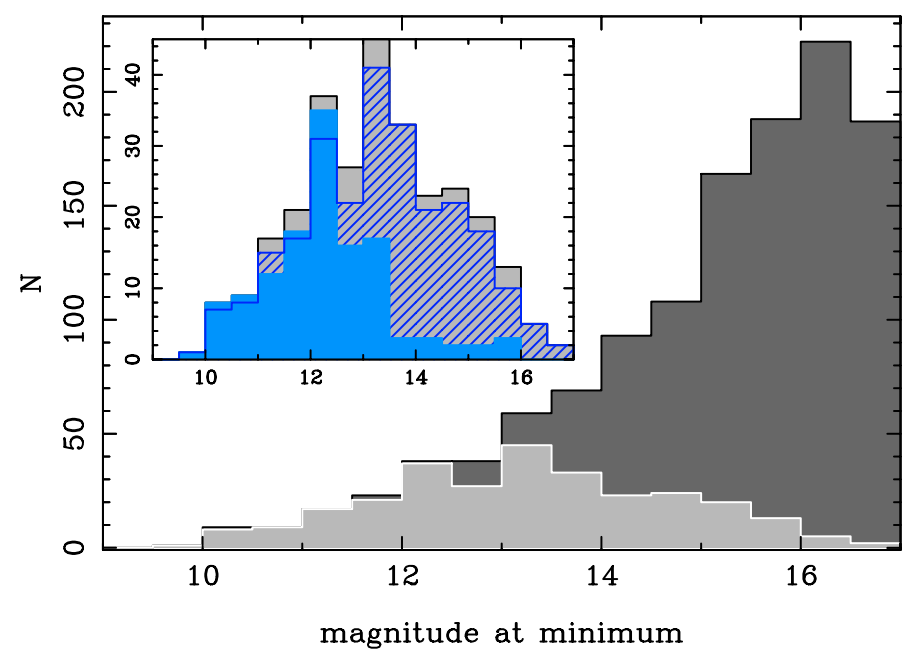

Fig. 1. Number of RR Lyr stars per magnitude (at minimum) bin observed from 2004 to 2006 . The observing material shown by the light grey histogram in the main window of the figure includes the GEOS RR Lyr Survey and the BAV CCD observations published in the IBVS. The dark grey histogram represents all the RR Lyr stars included in the GCVS. The enclosed histogram shows details of the contribution of the GEOS RR Lyr survey (filled blue) and the BAV (hatched blue).

Table 2. Inventory of the $\mathrm{O}-\mathrm{C}$ patterns in the RRab stars of our sample.

\begin{tabular}{lrl}
\hline \hline \multicolumn{1}{c}{ O-C pattern } & \multicolumn{1}{c}{$N$} & \multicolumn{1}{c}{ Representative cases } \\
\hline Constant period & 54 & \\
Increasing period & 27 & BN Aqr, RR Leo \\
Decreasing period & 21 & SW And, AH Cam, V964 Ori \\
Irregular slow variations & 17 & UY Boo, RW Dra \\
Single abrupt change & 4 & SZ Hya \\
Total & 123 & \\
\hline
\end{tabular}

while a second maximum occurs in the BAV histogram at magnitude 13.5 , corresponding to the use of larger telescopes by some observers.

\section{Data analysis}

We extracted from the GEOS database the RRab stars for which the times of maximum brightness span more than 50 years. Actually, the observations of RR Lyr stars started at the end of the XIXth century and for several objects the time baseline exceeds 100 years, with data in three different centuries. Throughout this time the observing techniques were very different (visual, photographic, photoelectric, CCD) and for each technique the accuracy of the data was not homogeneous, depending on the observer, the equipment and the number of measurements. Unfortunately, all that information was seldom known in the case of very old observations (often disseminated in several papers), which in turn are very important for establishing the $\mathrm{O}-\mathrm{C}$ trends. In these conditions, the attribution of weights to the maxima observed with different techniques was not practicable in a rigorous way. Moreover, when viable, this weighted procedure yielded results not significantly different from those obtained without weights; indeed, in these cases the datasets were mostly composed of data from a small number of observers (often using the same technique) and the resulting differences among weights were small. In a later stage, we also 
tried to assign weights to different subsets considering their scatter from a fitting $\mathrm{O}-\mathrm{C}$ curve (see Sect. 4), and this procedure also yielded similar results. Therefore, we are confident that our conclusions are not affected by the constraint of having assigned the same weight to all the maxima.

Particular care has been taken in the correct evaluation of the cycle values to be assigned to old maxima or after large gaps. Different O-C plots were obtained from different cycle countings, and abrupt jumps have been considered as suspicious. Sometimes, in the presence of large $\mathrm{O}-\mathrm{C}$ variations we could not reach a uniquevocal evaluation of the elapsed cycles, and therefore we did not consider the star for the subsequent analysis. During this process we also corrected some times of maximum brightness for obvious typographical errors; outliers (perhaps originated by errors in the decimal numbers) were also rejected, especially within otherwise well-defined small groups of maxima.

In several cases we corrected the linear elements since the respective $\mathrm{O}-\mathrm{C}$ values were linearly increasing or decreasing. The new periods, calculated on a very long time baseline, provided more reliable $\mathrm{O}-\mathrm{C}$ values. After this refinement, we started the analysis of the long-term behaviors. This procedure seems more reliable than comparing mean periods derived from groups of observations separated by very large gaps over a very long time baseline, as happens for globular cluster stars. Of course, in the case of galactic RR Lyr stars we met large gaps in the data, but we disregarded unclear cases.

Table 2 summarises the inventory of the different patterns we observed in the $\mathrm{O}-\mathrm{C}$ plots. Amongst the 123 cases, $81 \mathrm{RRab}$ stars are brighter than 12.5 at minimum. To evaluate the completeness of our sample, we note that the GCVS lists 164 RRab stars with a magnitude at minimum brighter than 12.5. Thus, our sample is complete at the $49 \%$ level; of course, there is no way to recover the remaining $51 \%$, since for these stars an insufficient number of times of maximum is available. Only in the future, with the progressive monitoring ensured by telescopes as TAROTs, will it be possible to increase the number of wellobserved RRab stars. We note that amongst the 84 unstudied variables, 56 have $\delta<0^{\circ}$.

The RRab stars showing a constant period for which we can provide improved elements are listed in Table 3. Formal errors at the $1 \sigma$-level from the least-squares fits are reported. The RRab stars whose elements cannot fit all the observed times of maxima are the most interesting cases. They are described in the next sections. We note that in spite of the short periods, RS Boo, AH Cam and EZ Cep are RRab stars. In particular, the GCVS classification of EZ Cep (RRc) is wrong; the HIPPARCOS photometry clearly shows a very steady ascending branch, typical of RRab stars (see Fig. 10 in Poretti 2001).

\section{Stars with a linearly variable period}

The most striking result is the detection of a large number of O-C plots showing a parabolic pattern when linear elements are used. The cause of this pattern is a regular period variation. The coefficients of the parabolic fits and their error bars have been calculated by using standard routines (Press et al. 1992). Sometimes they are not well defined; as a rule of acceptance the correlation coefficient $r$ of the least-squares parabola has to be larger than 0.70 . The times of maximum have been fitted with the elements

$C=T_{0}+P_{0} \cdot E+a_{3} \cdot E^{2}$ where $P_{0}$ is the period (in days) at epoch $T_{0}$ and $E$ is the cycle counter. Then, the linear rate $\mathrm{d} P / \mathrm{d} t(\mathrm{in}[\mathrm{d} / \mathrm{d}])$ is derived from

$\mathrm{d} P / \mathrm{d} t=2 \cdot a_{3} /\langle P\rangle$

where $\langle P\rangle$ is the average period, i.e., the ratio between the elapsed time (the difference between the first and last calculated maxima) and the elapsed cycles. In the literature it is more common to indicate the rate of period changes using the $\beta$ parameter, expressed in [d $\mathrm{Myr}^{-1}$ ] (e.g., Lee 1991; Jurcsik et al. 2001). The $\beta$ values can be calculated from the second-order fits by applying

$\beta=0.0732 \times 10^{10} \cdot a_{3} /\langle P\rangle$.

It indicates how much the period will change in $10^{6}$ years. In turn, this change can also be expressed as a fraction of the pulsation period (e.g., Smith \& Sandage 1981), i.e.:

$\alpha=\beta /\langle P\rangle$.

Tables 4 and 5 list the parabolic elements for RRab stars showing an increasing or decreasing period, respectively. With the aim of providing elements that will be directly useful in the planning of new observations, in each dataset the $E=0$ value has been assigned to the most recent time of maximum. Blazhko variables are also identified. The effect of having introduced the quadratic term can be evaluated for each star by comparing the lower and upper panels in Figs. 2 and 3.

Amongst the 27 RRab stars showing a linearly increasing period (Table 4 and Fig. 2), some cases are at the limit of acceptance $(0.70 \leq r \leq 0.76)$. In particular, the reliability of the older maxima is decisive in inferring the parabolic trends for V341 Aql, while that of the more recent ones is decisive for EZ Cep. In all the other cases the parabolic trend is clearly defined; in particular, $r>0.85$ in 20 cases. The standard deviations of the parabolic fits are less than $0.025 \mathrm{~d}$ in all cases except three (TV CrB, SV Eri and TV Leo). In particular, SV Eri is the RRab star showing the largest $\mathrm{O}-\mathrm{C}$ variation and the largest $\mathrm{d} P / \mathrm{d} t$ value, one order of magnitude larger than the average.

Amongst the 21 RRab stars showing a linearly decreasing period (Table 5 and Fig. 3) the reliability of the older maxima is decisive in inferring the parabolic trends for TW Boo and V394 Her. In the RV Cap case the parabolic trend is supported by both old and recent maxima, while the Blazhko effect (see next section) strongly contributes to reducing the $r$ value (0.69). In 17 cases we have $r>0.85$.

The standard deviations listed in Tables 4 and 5 have a mean value of $0.016 \mathrm{~d}$ and a median value of $0.014 \mathrm{~d}$. They can be considered as an estimate of the accuracy of the photographic and visual times of maximum brightness, since they constitute the largest fraction of the data. We can infer that the weighting procedure would not have been very sensitive to the more accurate (by a factor from 5 to 10) CCD and photoelectric data; these types of data are still rare and grouped in the last few decades. This could explain why we obtained similar results by applying the weighting procedure when possible (see Sect. 3). The above statistics and comparisons are quite satisfactory, and though the classification of some cases is somewhat doubtful, in general the observational scenario of stars with a linearly variable period is very well defined.

Just a few of the stars listed in Tables 4 and 5 were known to show a second-order term (BN Aqr, BR Aqr, CP Aqr, RW Cnc, W CVn, VZ Her, RR Leo, AV Peg, and AR Per), and in all cases there is an excellent agreement between the previous values (see for instance Oláh \& Szeidl 1978; and Szeidl et al. 1986 or, more in general, the GCVS, Kholopov 1988) and ours. 


\subsection{Other types of $\mathrm{O}-\mathrm{C}$ variations}

In our sample we can find examples of $\mathrm{O}-\mathrm{C}$ patterns that are too complicated to be described with a polynomial fit. The $\mathrm{O}-$ $\mathrm{C}$ values derived from linear elements (not listed because they are valid only as rough average values on the considered time baseline) for several stars show irregular oscillations, with different behaviors (Fig. 4). We note that in several cases there is no gap in the observations and therefore there is no ambiguity about the general $\mathrm{O}-\mathrm{C}$ behavior. The non-repeating $\mathrm{O}-\mathrm{C}$ oscillation shapes rule out light-time effects. A Blazhko effect can be partially responsible for some scatter, but not for the general trend.

The cases of SZ Hya, VV Peg, V759 Cyg and RU Cet are the simplest ones, since it seems that a single, abrupt change in the period has occurred. This also seems to be the case of UZ CVn; we rejected the parabolic fit since the left branch seems steeper than the right one, despite of the large scatter. XZ Cyg, RW Dra, RR Gem and RU CVn are a little more complicated; the changes occurred more than once, but still they are very sharp. The complexity of the O-C patterns increases in the cases of UY Boo, AR Her, Z CVn, ST Vir, AQ Lyr, RR Lyr itself, and RY Com, with several changes in the direction of the period variations. Other cases (EZ Lyr, RV UMa, BK Dra, SS Tau, BN Vul) show a smaller amplitude of the $\mathrm{O}-\mathrm{C}$ values, resulting in more scattered plots. However, the general behaviors are very similar to the previous ones, with two or more small changes in the periods.

\section{Searching for Blazhko and light-time effects}

The most obvious way to verify the reliability of the new elements, both linear and quadratic, is to analyze the residual $\mathrm{O}-\mathrm{C}$ values. To do that, we applied the iterative sine-wave leastsquares method (Vanicek 1979). The frequency analysis was performed in the interval $0.00-0.20 \mathrm{~cd}^{-1}$.

In several cases (SX Aqr, X Ari, RS Boo, RW Cnc, S Com, SU Dra, RZ Lyr, AV Peg, BH Peg and RY Psc) a very long period has been detected. Such a periodicity is often about half the time coverage and the amplitude is quite small. Therefore, we can infer that the parabolic fit is not perfect and that some systematic residuals were left, producing a spurious peak in the subsequent power spectrum. This feature can be noted looking at the $\mathrm{O}-$ $\mathrm{C}$ plots of the stars mentioned above in Figs. 2 and 3: the two branches seem to be asymmetric. We improved the $\mathrm{O}-\mathrm{C}$ fitting by calculating a third-order least-squares fit, but we obtained a significant third-order term in three cases only (RS Boo, RW Cnc, SU Dra). They produce similar rates of the period changes: $1.70 \times 10^{-10} \mathrm{~d} / \mathrm{d}$ (second-order fit) against $1.34 \times 10^{-10} \mathrm{~d} / \mathrm{d}$ (thirdorder fit) for SU Dra, $7.08 \times 10^{-10} \mathrm{~d} / \mathrm{d}$ (second-order fit) against $6.19 \times 10^{-10} \mathrm{~d} / \mathrm{d}$ (third-order fit) for RW Cnc, $1.42 \times 10^{-10} \mathrm{~d} / \mathrm{d}$ (second-order fit) against $1.70 \times 10^{-10} \mathrm{~d} / \mathrm{d}$ (third-order fit) for RS Boo. We note that new TAROT observations in the next decade will allow us to disentangle the $\mathrm{O}-\mathrm{C}$ behavior in these intriguing cases.

RZ Cet seems to be a particular case. The residual $\mathrm{O}-\mathrm{C}$ plot is quite unusual; a long term oscillation is clearly visible and seems to be superimposed on the parabolic trend (Fig. 3). The frequency analysis detects a low-frequency term at $f=$ $0.00008 \mathrm{~cd}^{-1}$, corresponding to $P=12500 \mathrm{~d}$, i.e., half the time coverage. The possibility of an erratic variation of the period is still plausible, but here the full amplitude is very large $(0.082 \mathrm{~d}$, i.e., $2.0 \mathrm{~h}$ ). The standard deviation after the introduction of the long period decreases from $0.034 \mathrm{~d}$ to $0.017 \mathrm{~d}$ and the fitting curve is perfectly sine shaped. These clues support the possibility of a light-time effect, but the gap in the $\mathrm{O}-\mathrm{C}$ coverage hampers complete certainty.

The presence of a Blazhko effect has been reported for SW Boo, SW Psc and FK Vul, but available times of maximum light are too scant to perform a reliable frequency analysis. The frequency analysis of the residual O-Cs related to SW And, DM Cyg, RZ Lyr and BH Peg did not detect any evident peak in the power spectra, though these RR Lyr variables are reported to be Blazhko stars. However, in some stars the amplitude of the Blazhko period changes over time, while in others the Blazhko effect might be more evident in the periodic modulation of the amplitude than in the $\mathrm{O}-\mathrm{C}$ values. Therefore, in both cases the amplitudes of the $\mathrm{O}-\mathrm{C}$ shifts could be too small to rise above the noise level. In other cases the detection has been positive. They constitute a convincing demonstration of the quality of the database.

$R V$ Cap - Kholopov (1988) reports a Blazhko period of $225.5 \mathrm{~d}$. Our frequency analysis refined this value to $222.96 \pm$ $0.14 \mathrm{~d}$. Figure 5 shows the power spectrum (lower panel) with the peak at $f=0.00448 \mathrm{~cd}^{-1}$ clearly standing out. The full amplitude of the $\mathrm{O}-\mathrm{C}$ variation is $0.045 \mathrm{~d}$. In spite of the heterogeneous observational techniques, the $\mathrm{O}-\mathrm{C}$ curve appears quite evident when folding the $\mathrm{O}-\mathrm{C}$ over the $222.96 \mathrm{~d}$ period (upper panel; $T_{0}=2430027.87$ ). The Blazhko effect is responsible for the large scatter observed in the $\mathrm{O}-\mathrm{C}$ plot of RV Cap in Fig. 3 and for the low $r$ value (0.69).

AH Cam - The Blazhko period of AH Cam is one of the shortest known so far. Smith et al. (1994) identified a period of $11 \mathrm{~d}$ by means of two photometric runs in 1989-90 and 199192 (covering 17 and 13 nights, respectively). The light curves show evident changes in shape and amplitude. The Blazhko effect is also recoverable in the times of maximum light spanning 56 years (Fig. 6). The frequency analysis unambiguously identified the peak at $0.0894 \mathrm{~cd}^{-1}$ (lower panel), and the $\mathrm{O}-$ $\mathrm{C}$ plot over the refined period at $11.1808 \pm 0.0004 \mathrm{~d}\left(T_{0}=\right.$ HJD 2438040.96 ) shows a full amplitude of $0.024 \mathrm{~d}$ (upper panel).

$R S B o o$ - The power spectrum reveals the low-frequency peak accounting for the slightly asymmetric $\mathrm{O}-\mathrm{C}$ behavior (see above). However, a second peak is visible at $534.24 \mathrm{~d}$, very close to the value given by Oosterhoff (1949), i.e., $533 \mathrm{~d}$. The full amplitude is $0.010 \mathrm{~d}$. On the other hand, there is no evidence of the additional period in the 58-62 d range suggested by Kanyo (1980); its amplitude, if real, is probably too small to be detected.

TT Cnc - The power spectrum shows a peak at $f=$ $0.01145 \mathrm{~cd}^{-1}$, corresponding to $87.35 \mathrm{~d}$, close to the value determined by Szeidl (1968), i.e., 89 d. The resulting O-C curve shows some scatter.

CX Lyr - The standard deviation of the $\mathrm{O}-\mathrm{C}$ values with respect to the parabolic elements is quite high $(0.036 \mathrm{~d})$. The spectral window of the data is poor and hence the frequency analysis detects several peaks with comparable heights. The most convincing peaks correspond to periods of $227 \mathrm{~d}$ and $128 \mathrm{~d}$. The $\mathrm{O}-\mathrm{C}$ values folded over the two periods yield very similar plots, with a small preference for the $128 \mathrm{~d}$ curve; the full amplitude is $0.070 \mathrm{~d}$ and the standard deviation decreases to $0.027 \mathrm{~d}$. No Blazhko effect was previously reported on CX Lyr.

\section{Period variations as evolutionary effects}

The $\mathrm{d} P / \mathrm{d} t$ values listed in Tables 4 and 5 constitute the first measurements of the rate of period changes in the sample of the best 

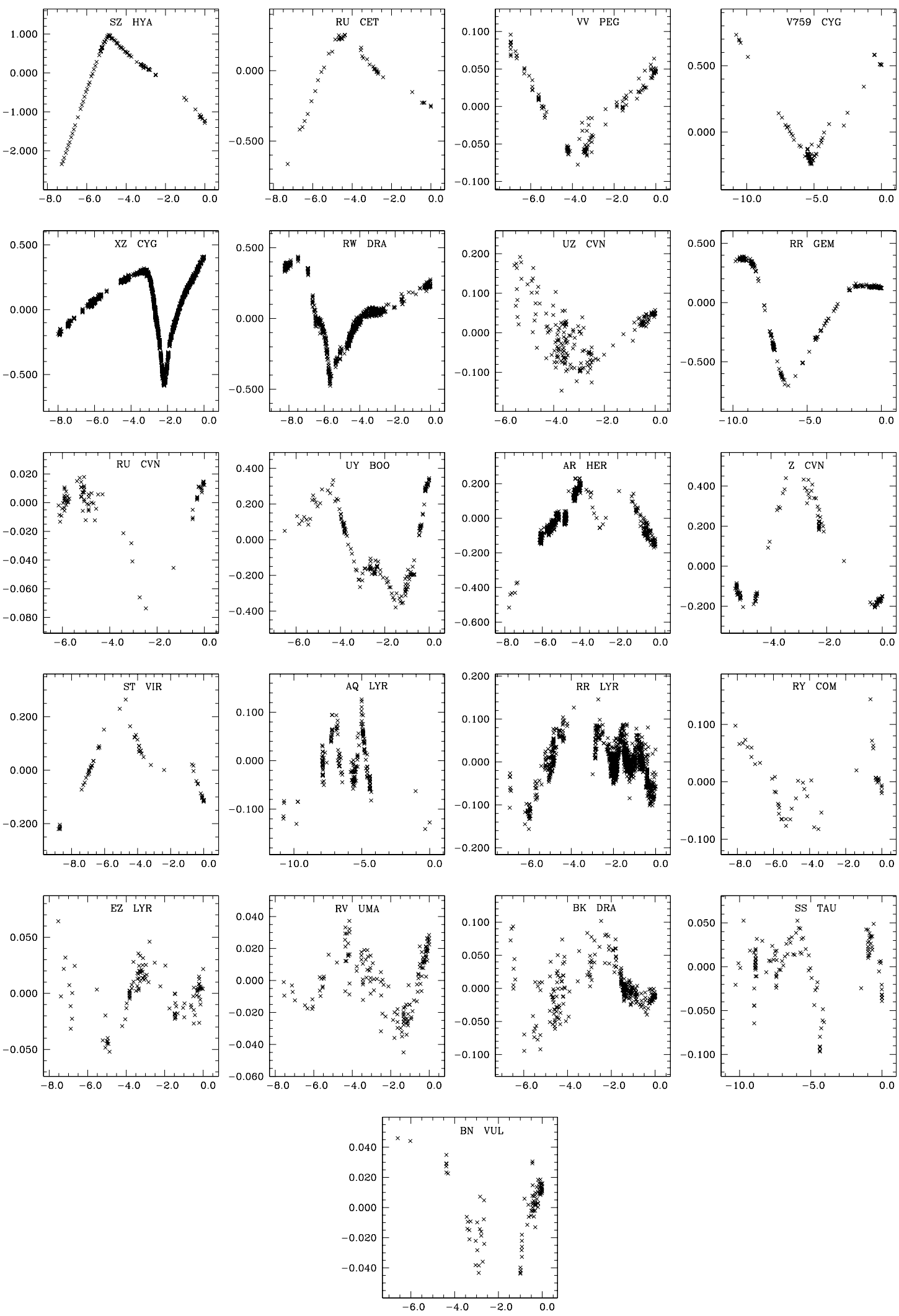

Fig. 4. O-C values for RRab stars calculated with a linear fit and showing irregular variations. They are ordered by increasing complexity of their $\mathrm{O}-\mathrm{C}$ patterns. On the $x$-axis we plot the elapsed cycles $(E / 10000)$; on the ordinate one we plot the $\mathrm{O}-\mathrm{C}$ values in days.

observed RR Lyr stars belonging to the Milky Way field. It is noteworthy that all the values, both positive and negative, have the same order of magnitude and therefore they should have a common origin. Such an origin cannot be ascribed to a particular cause (as it could for period variations induced by tidal effects or by particular instabilities), but should be provoked by 

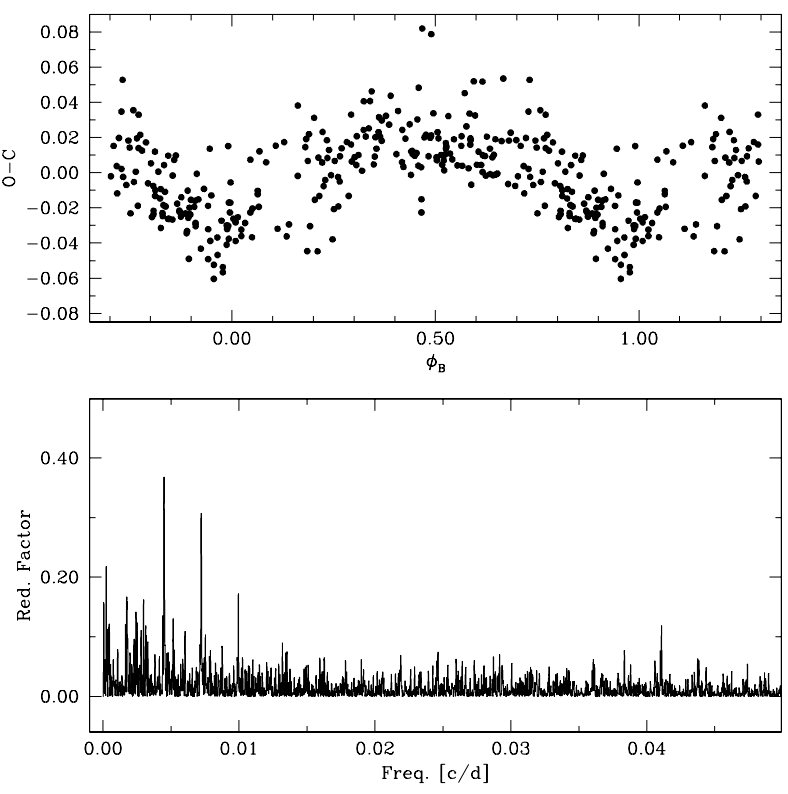

Fig. 5. The long-period Blazhko effect of RV Cap. Lower panel: power spectrum of the $\mathrm{O}-\mathrm{C}$ values with respect to the parabolic elements; the highest peak is at $0.00448 \mathrm{~cd}^{-1}$. Upper panel: the same $\mathrm{O}-\mathrm{C}$ values folded with the Blazhko period of $222.96 \mathrm{~d}$. O-C measure unit is days.
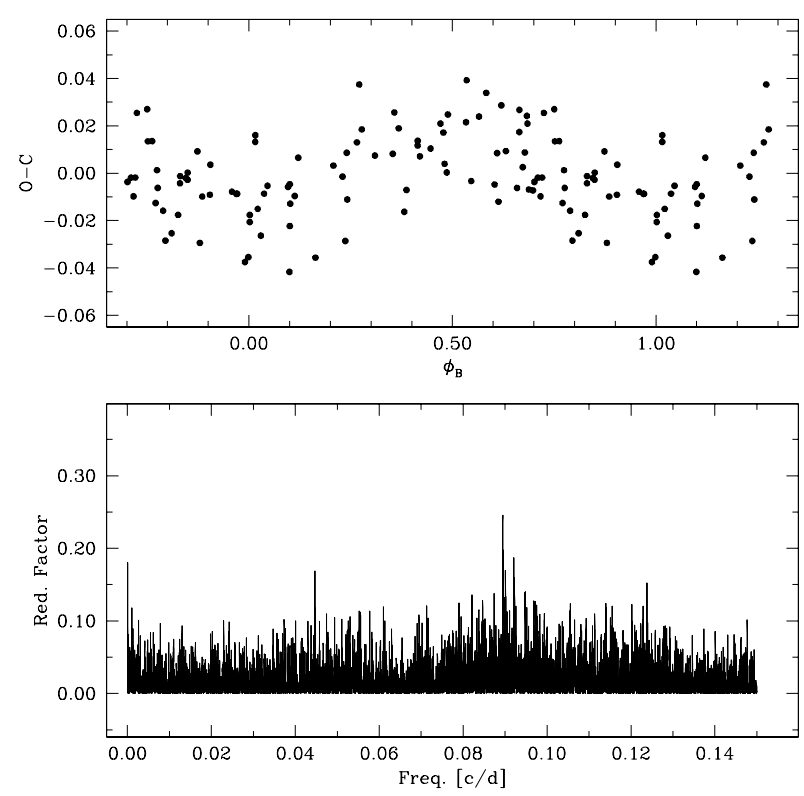

Fig. 6. The short-period Blazhko effect of AH Cam. Lower panel: power spectrum of the $\mathrm{O}-\mathrm{C}$ values with respect to the parabolic elements; the highest peak is at $0.0894 \mathrm{~cd}^{-1}$. Upper panel: the same $\mathrm{O}-\mathrm{C}$ values folded with the Blazhko period of $11.1808 \mathrm{~d}$. O-C measure unit is days.

a quite general phenomenon, involving a whole population of stars. Though we cannot rule out the possibility that an individual star amongst those listed in Tables 4 and 5 is in a particular transition phase (see Sect. 6.3), the immediate answer is that the period variations are caused by long-term stellar evolution; indeed, RR Lyr stars change their radii and in turn their fundamental radial periods when moving along the horizontal branch.
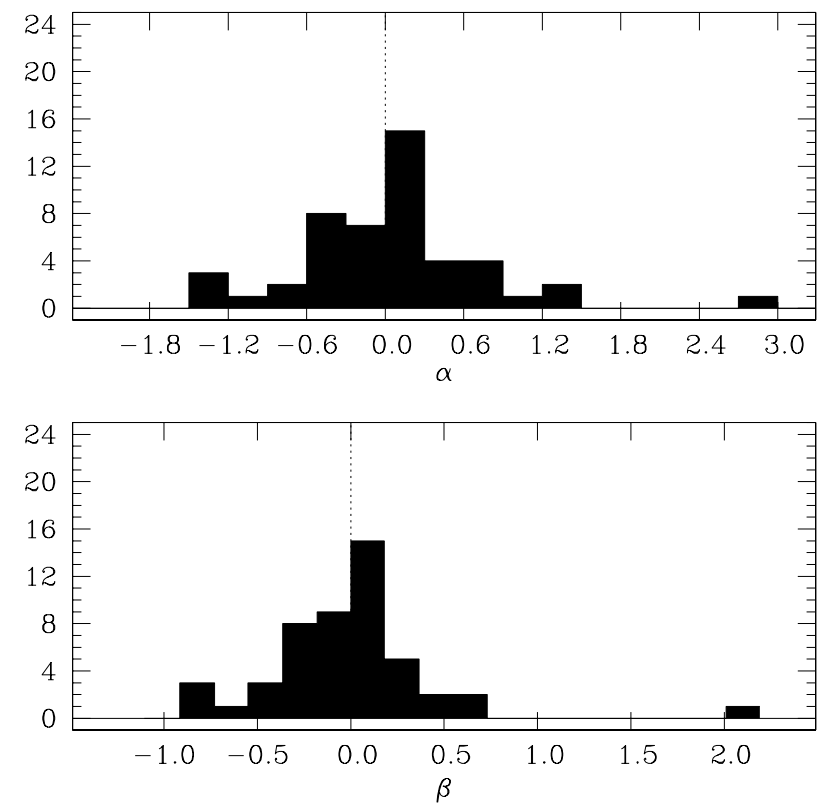

Fig. 7. Distribution of the rates of period changes. Constant periods (i.e., $\beta=0.0$ ) are not shown. Note the extreme case of SV Eri in the positive part.

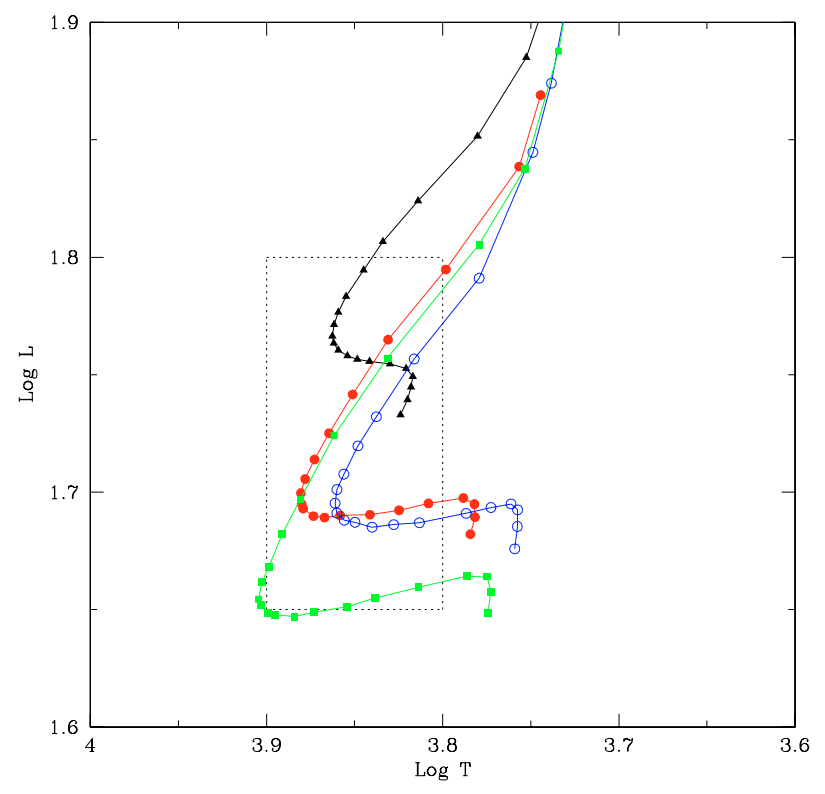

Fig. 8. Examples of tracks showing blueward evolution at the beginning of the horizontal branch evolution. Triangles (in black) indicate a track with $Z=0.0001$ and $M=0.86 M_{\odot}$, filled circles (in red) a track with $Z=0.0004$ and $M=0.74 M_{\odot}$, empty circles (in blue) a track with $Z=$ 0.0007 and $M=0.72 M_{\odot}$, squares (in green) a track with $Z=0.0010$ and $M=0.68 M_{\odot}$. The box indicates the instability strip domain (Lee 1993).

The order of magnitude of the period changes we detected is that expected from evolutionary models: Lee (1991) reports $\beta$ values in the range $0.0-0.3 \mathrm{~d} \mathrm{Myr}^{-1}$. Moreover, our values are similar to those reported by Jurcsik et al. (2001) in the case of $\omega$ Cen RR Lyr stars $\left(\beta\right.$ mean rate of $\left.0.15 \mathrm{~d} \mathrm{Myr}^{-1}\right)$ and discussed as evolutionary changes. Therefore, our analysis, providing a reliable 


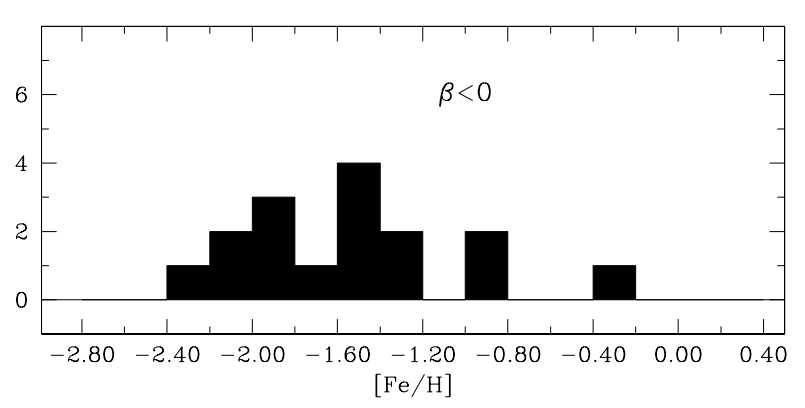

Fig. 9. The distribution of the $[\mathrm{Fe} / \mathrm{H}]$ values (as reported by Layden 1994) of the stars showing decreasing periods (16 out of 21 cases).

estimate of the rate of period changes in field RR Lyr stars, allowed us to perfom a closer investigation of the stellar evolution along the horizontal branch.

\subsection{Comparison between stars with period changes of opposite sign}

The histograms shown in Fig. 7 summarise the properties of our sample. They provide evidence that a large fraction of RR Lyr stars experience appreciable changes in their structure in the time now covered by observations. The first immediate result is that the blueward evolution (decreasing periods) is as common as the redward one (increasing periods). Consequently, RR Lyr stars seem to be an excellent laboratory to verify the modifications of the internal structure caused by stellar evolution under different conditions (e.g., contraction and expansion). On the other hand, we remind the reader that in 54 cases (i.e., a number of cases similar to the number of RR Lyr stars showing period variations) we did not detect a significant period variation. No period variation could occur at the turning point in the evolutionary tracks, but a constant period probably means that there are phases in the instability strip crossing when changes are not large enough to be measurable in 100 years or so.

When limiting to cases where a period variability is noted, we get a similar distribution between negative and positive rates (Fig. 7) for our field RRab stars. We also note that the period ranges are nearly coincident in the two samples; in particular, we have a mean and median value of $0.53 \mathrm{~d}$ for stars with increasing period, and a mean and median value of $0.51 \mathrm{~d}$ for stars with decreasing period. This similarity is not observed for RRab stars in galactic clusters (Lee 1991; Jurcsik et al. 2001), where positive rates are largely more frequent.

In our opinion, the large number of galactic stars showing decreasing periods is a strong confirmation of the evolutionary tracks provided by Sweigart (1987) and Lee \& Demarque (1990). Most of these tracks cross the instability strip at high luminosities in the redward direction. However, Fig. 8 shows that for some combinations of masses and metallicities (e.g., by increasing the mass of the model with a lower metallicity), a blueward evolution at the beginning of the horizontal branch phase is predicted, both at high luminosity $(Z=0.0001$ and $\left.M=0.86 M_{\odot}\right)$ and at low luminosity $(Z=0.0010$ and $M=0.68 M_{\odot}$ ), and such blueward paths actually cross the instability strip domain. The theoretical sequences calculated by Dorman (1992) predict a blueward evolution at slightly lower luminosities, crossing the instability strip in fewer cases (e.g., Fig. 7 in Jurcsik et al. 2001). In general, all theoretical models predict a blueward evolution in connection with the prevalence of the H-shell burning over the He-central burning. The fact that the intersection between these blueward tracks and the instability strip is predicted only for particular combinations of physical parameters is compensated by the longer lifetimes on the blueward path relative to the redward one (see next section). Therefore, once we have established that the blueward crossing occurs, the slow migration could explain why we observe RRab stars in this phase.

To investigate the real agreement between the input parameters of the evolutionary tracks shown in Fig. 8 and the stars of our sample, we considered the $[\mathrm{Fe} / \mathrm{H}]$ values determined by Layden (1994) by means of homogeneous low-to-moderate dispersion spectra. Sixteen stars with decreasing periods are included in Layden's sample; we get $[\mathrm{Fe} / \mathrm{H}]<-1.20$ in 13 cases and a median value of $[\mathrm{Fe} / \mathrm{H}]=-1.48$ (Fig. 9). These $[\mathrm{Fe} / \mathrm{H}]$ values translate into $Z \leq 0.0010$ and $Z=0.0007$ (e.g., Pietrinferni et al. 2004). Therefore, the observed metallicities are in the same range of those used to generate the tracks shown in Fig. 8. A similar distribution is obtained for stars with increasing periods; in 20 cases out of 24 we observe $[\mathrm{Fe} / \mathrm{H}]<-1.20$ and the median value is $[\mathrm{Fe} / \mathrm{H}]=-1.52$. This supports the hypothesis that all the stars with increasing and decreasing periods have similar characteristics, but the latter ones are less evolved than the former.

\subsection{The rate of period changes}

To avoid influence from a few very large positive or negative rates, we calculated the median values of the rates of the period changes to characterise the two distributions shown in Fig. 7. We obtained $\beta=+0.14, \alpha=+0.26$ for the 27 stars with increasing periods and $\beta=-0.20, \alpha=-0.43$ for the 21 stars with decreasing periods. As already shown in early investigations by Sandage (1957) and then confirmed by Lee (1991) and Pietrinferni et al. (2004), the estimate of the horizontal branch lifetime is about $\sim 10^{8}$ years, and a star spends $\sim 1 / 3$ of its life in the instability strip. Moving uniformly through the strip with time, the corresponding rate of period change should be around $\alpha=0.02$ : Fig. 7 provides evidence of rates one order of magnitude greater.

However, we have to take into account that when observing a star for 100 years we are monitoring a fraction corresponding to $10^{-5}$ of the lifetime spent crossing the strip. The rates of the period changes we measure are a sort of instantaneous value, which refers to a particular stage in the horizontal branch phase. Indeed, it is quite obvious that the stars cannot maintain a constant rate of some $0.1 \mathrm{~d} \mathrm{Myr}^{-1}$ for several $10^{6}$ years, since their periods would assume values largely outside the RRab range $(0.4-0.8 \mathrm{~d})$ and thus physically meaningless. Therefore, we should definitely refrain from considering the observed rates as the constant rate of the instability strip crossing of a specific stellar model. Such large variations (units of $0.1 \mathrm{~d} \mathrm{Myr}^{-1}$ ) must last for a few $10^{6}$ years only. On the other hand, the 54 stars showing a constant period could be in the middle of their long crossing of the instability strip.

The obvious interpretation of Fig. 7 is to consider that the observed rates are those corresponding to the phases when the stars change their periods with the fastest rate. The rate spread is caused both by the different physical parameters of the stars and by the small differences in age. When considering the evolutionary rates provided by Lee (1991), it seems that large $\beta$ rates occur only at the end of the instability strip crossing (i.e., roughly, 1/20 of its horizontal branch lifetimes). However, such a proportion would imply a huge number of RR Lyr stars with nearly constant periods and a few stars with large $\beta$ values. In our 
sample we found a 2:1 ratio. To explain the low number of stars with constant period we should admit that amongst the galactic RR Lyr stars there is a predominance of low-mass stars: the theoretical models predict (see Fig. 1 in Lee 1991) that these stars cross the instability strip very quickly, close to the end of their horizontal branch lifetime. The case of SV Eri can support this point. It has a long period $(0.71 \mathrm{~d})$, close to the observational limit of RR Lyr periods. The theory predicts a large positive rate in this case and indeed we observe $\alpha=2.97$, actually a huge value (see below). XX And has a similar period value (0.72 d), but its rate of period change is one order of magnitude smaller $(\alpha=0.20)$. Thus, SV Eri seems to have entered the rapid final phase, and it should be considered a very peculiar object experiencing a rapid final evolution.

The median values also suggest that galactic RR Lyr stars experienced slightly faster period decreases than increases. To evaluate the physical meaning of this fact, we need to compare them more closely with the lifetimes of the blueward and redward crossings. Actually, the blueward crossings are about 1.6 times longer than the redward. As an example, the two tracks with $Z=0.0004$ and $Z=0.0007$ in Fig. 8 (i.e., those indicated by filled and empty circles, respectively) yield 33 and $28 \mathrm{Myr}$ for the blueward evolution and 21 and 17 Myr for the redward evolution. Moreover, the stars should change their radius to a lesser extent in the blueward evolution than in the redward one $(0.13$ against 0.20 , in $\log R$ ). Therefore, at first glance, the positive $\beta$ values should be on the average greater (also in absolute value) than the negative ones, since a larger period variation occurs in a shorter time. This expectation seems to be contradicted by the histograms shown in Fig. 7. The contradiction could be partially explained by taking into account the observation that the short lifetimes on the final part of the redward evolution strongly reduce the possibility of observing these stars. Nevertheless, the RRab stars showing rapid period decreases still need more detailed theoretical investigations. For example, their large number could result from a burst in the stellar formation process in our galaxy.

Finally, we have to address a possible discrepancy between the observed and predicted rates of the period changes. The theoretical evolutionary rates calculated by Lee (1991) and recalled above predict $\beta$ values smaller than 0.30 for almost all the stars. $\beta$ values larger than 0.30 (stars with very low mass, $M=0.68 M_{\odot}$, and well-defined metallicity, $Z=0.0004$ ) are only reported in exceptional cases and the lifetimes of these phases are very short. In our sample we have 18 stars with $0<\beta<0.30$ and 9 stars with $\beta>0.30$. Also in this case, the $2: 1$ ratio seems too small to be caused by the presence of exceptional cases. Furthermore, the $\alpha=2.97$ value of SV Eri recalled above is much higher than expected. Smith \& Sandage (1981, also quoting Iben 1971) indicate $\alpha=0.5$ as an extreme value, but such a value is not an uncommon one (see Fig. 7) and is much smaller than the SV Eri value.

Our conclusion is that the theoretical models should be fine tuned to match the observed rates in a better way, now that the extensive GEOS database allows us to measure them in a reliable sample.

\subsection{Erratic changes}

During the final phase of the helium core burning it is possible that instabilities occur and that period variations are not regular, both around a constant value or superimposed on the general trend (Sweigart \& Demarque 1973). This possibility has been suggested by Sweigart \& Renzini (1979) and has been invoked by Lee (1991) to explain the few cases of negative values in the rate of period changes. RR Lyr stars showing blueward evolution have been considered as suspicious, invoking period changes caused by temporary instabilities, but we are providing evidence that the number of RR Lyr stars subject to blueward evolution is similar to the number of stars subject to the redward evolution. Therefore, the erratic changes should be considered as representative of a particular evolutionary stage, as the final helium core burning could be, but not as an ad hoc solution to explain negative rates only. We also stress that the erratic changes occur in both directions (see Fig. 4). In our opinion, the sudden, sharp period changes occurring in the cases similar to SZ Hya could be the result of particular temporary instabilities, which can also produce sudden blueward excursions (Sweigart \& Renzini 1979). We also stress that only a comprehensive analysis performed on a large database can avoid overlooking these sudden changes as evolutionary ones.

\section{Conclusions}

The analysis of $\mathrm{O}-\mathrm{C}$ variations over a timescale of 100 years or more has proved to be a powerful tool for providing quantitative tests of the stellar evolution of the horizontal branch stars. We can stress some well-established observational facts:

1. RRab stars experiencing blueward evolution (i.e., period decreases) are quite common, only slightly less so than RRab stars experiencing redward evolution (i.e., period increases). The period ranges covered by the two groups are very similar and the mean and median period values are nearly coincident;

2. the absolute values of period changes are larger than expected. Also in the extreme case of the rapid-evolving star SV Eri the rate is much larger than expected;

3. the $\mathrm{O}-\mathrm{C}$ behavior can be very complicated in some cases, with abrupt or irregular period variations, rather than monotonic. The regular variations caused by the light-time effect (and hence duplicity), often invoked to explain large $\mathrm{O}-\mathrm{C}$ excursions, are not convincingly observed in our extensive sample. The physical explanations should be searched in the stellar structure;

4. Blazhko effect is often superimposed on secular changes, but the monotonic trend due to evolutionary variations still remains visible.

As a general conclusion about the comparison between our observational results and the theoretical predictions, we claim that there is a very powerful feedback between the two approaches. In particular, theoretical investigations should take into account that we have observational evidence of many RR Lyr stars showing blueward evolution. The theoretical models should also match the observed $\beta$ values in a more satisfactory way, as these seem to be higher than expected, both for redward and blueward evolutions. On the other hand, the observational effort to monitor RR Lyr stars should be continued, possibly extended to stars at fainter magnitudes, and the accuracy of the maximum time determinations should be improved (by using automated telescopes), thus obtaining the same information on a shorter time baseline.

Acknowledgements. The outlines of this project have been sketched during several GEOS meetings, where the different knowledge of amateur and professional astronomers found a very profitable synthesis. The active participation of N. Beltraminelli, M. Benucci, R. Boninsegna, M. Dumont, J. Fabregat, F. Fumagalli, D. Husar, A. Manna, J.C. Misson, J. Remis, and J. Vialle to these discussions is gratefully acknowledged. The authors also thank M. Catelan, 
S. Degl'Innocenti, H. Smith, and L. Szabados for useful comments on a first draft of the manuscript. E.P. acknowledges support from the INAF project 39/2005. The present study has used the SIMBAD database operated at the Centre de Données Astronomiques (Strasbourg) in France.

\section{References}

Agerer, F., \& Hübscher, J. 2002, IBVS 5296 (BAV Mitteilungen No. 152) Agerer, F., \& Hübscher, J. 2003, IBVS 5485 (BAV Mitteilungen No. 160) Boër, M., Atteia, J. L., Bringer, M., et al. 2001, A\&A, 378, 76

Bringer, M., Boër, M., Peignot, C., Fontan, G., \& Merce, C. 1999 A\&AS 138, 581

Damerdji, Y., Klotz, A., \& Boër, M. 2007, AJ, 133, 1470

Dorman, B. 1992, ApJS, 81, 221

Hübscher, J. 2005, IBVS 5643 (BAV Mitteilungen No. 172)

Hübscher, J., Paschke, A., \& Walter, F. 2005, IBVS 5657 (BAV Mitteilungen No. 173)

Hübscher, J., Paschke, A., \& Walter, F. 2006, IBVS 5731 (BAV Mitteilungen No. 178)

Iben, I. 1971, PASP 83, 697

Jurcsik, J., Clement, C., Geyer, E. H., \& Domsa, I. 2001, AJ, 121, 951

Kanyo, S. 1980, IBVS 1832

Kholopov, P. N., et al. 1988, General Catalogue of Variable Stars, 4th edn. (Moscow: Nauka Publishing House), ed. by P. N. Khopolov

Klotz, A., Gendre, B., Stratta, G., et al. 2006, A\&A, 451, L39

Layden, A. C. 1994, AJ, 108, 1016

Le Borgne, J. F., Klotz, A., \& Boër M. 2004, IBVS 5568 (GEOS Circular RR 21)

Le Borgne, J. F., Klotz, A., \& Boër, M. 2005a, IBVS 5622 (GEOS Circular RR 24)
Le Borgne, J. F., Klotz, A., \& Boër, M. 2005b, IBVS 5650 (GEOS Circular RR 25)

Le Borgne, J. F., Klotz, A., \& Boër, M. 2006a, IBVS 5686 (GEOS Circular RR 26)

Le Borgne, J. F., Klotz, A., \& Boër, M. 2006b, IBVS 5717 (GEOS Circular RR 28)

Le Borgne, J. F., Klotz, A., \& Boër, M. 2007, IBVS 5767 (GEOS Circular RR 29) Lee, Y. W. 1991, ApJ, 367, 524

Lee, Y. W. 1993, in New Perspectives on Stellar Pulsation and Pulsating Variable Stars, ed. J. M. Nemec \& J. M. Matthews (Cambridge Univ. Press), IAU Coll., 139, 294

Lee, Y. W., \& Demarque, P. 1990, ApJS, 73, 709

Oláh, K., \& Szeidl, B., Communications of the Konkoly Observatory, 71

Oosterhoff, P. Th. 1949, BAN, 10, 101

Pietrinferni, A., Cassisi, S., Salaris, M., \& Castelli, F. 2004, ApJ, 612, 168 Poretti, E. 2001, A\&A, 371, 986

Press, W. H., Teukolsky, S. A., Vetterling, W. T., \& Flannery, B. P. 1992, Numerical Recipes (Cambridge: Cambridge U. Press), UK

Sandage, A. 1957, ApJ, 126, 326

Smith, H. A., \& Sandage, A. 1981, AJ, 86, 1870

Smith, H. A., Matthews, J. M., Lee, K. M., et al. 1994, AJ, 107, 679

Sweigart, A. V. 1987, ApJS, 65, 95

Sweigart, A. V., \& Demarque, P. 1973, in Variable Stars in Globular Clusters and in Related Systems, ed. J. D. Fernie (Dordrecht: Reidel), IAU Coll. 21, 221

Sweigart, A., \& Renzini, A. 1979, A\&A, 71, 66

Szeidl, B. 1968, IBVS, 278

Szeidl, B., Oláh, K., \& Miszer, A., Communications of the Konkoly Observatory, 89

Tsesevich, V. P. 1969, RR Lyrae stars, Israel program for scientific translation. Vanicek, P. 1979, Ap\&SS, 12, 10 


\section{Online Material}


Table 3. Refined linear elements for stars showing a constant period. The note ${ }^{B}$ beside the value of the standard deviation indicates the stars having a known Blazhko effect.

\begin{tabular}{|c|c|c|c|c|c|c|}
\hline \multicolumn{2}{|c|}{ Star } & \multirow{2}{*}{$\begin{array}{r}N_{\max } \\
66\end{array}$} & \multirow{2}{*}{$\begin{array}{c}\text { Time coverage } \\
\text { [years] }\end{array}$} & \multirow{2}{*}{$\begin{array}{c}\text { Epoch } \\
{[\mathrm{HJD}-2400000]} \\
36109.5000 \pm 0.0030\end{array}$} & \multirow{2}{*}{$\begin{array}{c}\begin{array}{c}\text { Period } \\
{[\mathrm{d}]}\end{array} \\
0.61691445 \pm 0.00000014\end{array}$} & \multirow{2}{*}{$\begin{array}{c}\begin{array}{c}\text { s.d. } \\
\text { [d] }\end{array} \\
0.0169\end{array}$} \\
\hline AT & And & & & & & \\
\hline DE & And & 29 & 64 (1935-1999) & $39764.5234 \pm 0.0033$ & $0.45363536 \pm 0.00000019$ & 0.0176 \\
\hline GV & And & 54 & $62(1937-1999)$ & $40171.3320 \pm 0.0050$ & $0.52809310 \pm 0.00000033$ & 0.0319 \\
\hline OV & And & 100 & 75 (1929-2004) & $39469.2891 \pm 0.0012$ & $0.47058114 \pm 0.00000007$ & 0.0111 \\
\hline $\mathrm{TZ}$ & Aqr & 34 & $92(1915-2007)$ & $37548.9023 \pm 0.0022$ & $0.57119429 \pm 0.00000010$ & 0.0128 \\
\hline $\mathrm{YZ}$ & Aqr & 51 & $112(1894-2006)$ & $33343.2617 \pm 0.0033$ & $0.55193269 \pm 0.00000017$ & 0.0218 \\
\hline DN & Aqr & 35 & 71 (1936-2007) & $40915.3125 \pm 0.0050$ & $0.63375407 \pm 0.00000039$ & 0.0268 \\
\hline $\mathrm{TZ}$ & Aur & 140 & 94 (1913-2007) & $37946.4922 \pm 0.0006$ & $0.39167482 \pm 0.00000002$ & 0.0051 \\
\hline $\mathrm{BH}$ & Aur & 41 & $100(1906-2006)$ & $37352.4727 \pm 0.0024$ & $0.45608902 \pm 0.00000007$ & 0.0086 \\
\hline SS & $\mathrm{Cnc}$ & 104 & 96 (1909-2005) & $36201.3906 \pm 0.0012$ & $0.36733848 \pm 0.00000003$ & 0.0117 \\
\hline $\mathrm{RX}$ & $\mathrm{CVn}$ & 56 & $98(1907-2005)$ & $36904.2266 \pm 0.0024$ & $0.54002589 \pm 0.00000012$ & 0.0176 \\
\hline $\mathrm{AL}$ & $\mathrm{CMi}$ & 41 & $82(1925-2007)$ & $36607.3047 \pm 0.0046$ & $0.55051273 \pm 0.00000020$ & 0.0243 \\
\hline UU & Cet & 30 & $82(1917-1999)$ & $37582.4336 \pm 0.0077$ & $0.60607427 \pm 0.00000056$ & $0.0380^{B}$ \\
\hline SU & Col & 25 & $65(1937-2002)$ & $39410.5234 \pm 0.0064$ & $0.48735806 \pm 0.00000035$ & 0.0302 \\
\hline ST & Com & 62 & $90(1916-2006)$ & $37652.6680 \pm 0.0022$ & $0.59892809 \pm 0.00000011$ & 0.0163 \\
\hline W & Crt & 23 & $70(1935-2005)$ & $39910.8633 \pm 0.0014$ & $0.41201425 \pm 0.00000007$ & 0.0063 \\
\hline UY & Cyg & 106 & 105 (1901-2006) & $34862.3203 \pm 0.0014$ & $0.56070578 \pm 0.00000006$ & 0.0116 \\
\hline BV & Del & 28 & 77 (1928-2005) & $39354.2539 \pm 0.0037$ & $0.42345089 \pm 0.00000015$ & 0.0184 \\
\hline BT & Dra & 63 & $101(1905-2006)$ & $35868.4648 \pm 0.0028$ & $0.58867335 \pm 0.00000014$ & 0.0205 \\
\hline SZ & Gem & 74 & 85 (1922-2007) & $38360.8438 \pm 0.0015$ & $0.50113541 \pm 0.00000007$ & 0.0108 \\
\hline GI & Gem & 63 & $66(1941-2007)$ & $36971.7148 \pm 0.0016$ & $0.43326673 \pm 0.00000007$ & 0.0122 \\
\hline TW & Her & 226 & 94 (1912-2006) & $36784.3828 \pm 0.0004$ & $0.39960003 \pm 0.00000002$ & 0.0062 \\
\hline $\mathrm{BD}$ & Her & 62 & 97 (1900-1997) & $33064.4766 \pm 0.0043$ & $0.47390789 \pm 0.00000025$ & 0.0317 \\
\hline $\mathrm{EE}$ & Her & 33 & $57(1936-1993)$ & $38853.6250 \pm 0.0026$ & $0.49553666 \pm 0.00000025$ & 0.0129 \\
\hline V524 & Her & 122 & $56(1930-1986)$ & $36318.5156 \pm 0.0032$ & $0.48186663 \pm 0.00000022$ & 0.0326 \\
\hline GO & Hya & 39 & 78 (1929-2007) & $35821.6641 \pm 0.0052$ & $0.63643533 \pm 0.00000028$ & 0.0317 \\
\hline $\mathrm{RX}$ & Leo & 23 & $72(1935-2007)$ & $38431.9336 \pm 0.0055$ & $0.65341568 \pm 0.00000027$ & 0.0115 \\
\hline ST & Leo & 96 & $80(1926-2006)$ & $39260.4219 \pm 0.0007$ & $0.47798404 \pm 0.00000004$ & 0.0068 \\
\hline WW & Leo & 40 & $72(1935-2007)$ & $39801.6211 \pm 0.0031$ & $0.60284597 \pm 0.00000021$ & 0.0197 \\
\hline AA & Leo & 22 & $52(1953-2005)$ & $47271.3828 \pm 0.0021$ & $0.59865355 \pm 0.00000023$ & 0.0088 \\
\hline $\mathrm{AX}$ & Leo & 35 & 79 (1927-2006) & $37026.5742 \pm 0.0041$ & $0.72682691 \pm 0.00000023$ & 0.0230 \\
\hline $\mathrm{V}$ & $\mathrm{LMi}$ & 34 & 95 (1912-2007) & $36630.6094 \pm 0.0018$ & $0.54391927 \pm 0.00000006$ & 0.0065 \\
\hline VY & Lib & 21 & 77 (1914-1991) & $33773.3203 \pm 0.0035$ & $0.53394097 \pm 0.00000028$ & 0.0162 \\
\hline $\mathrm{TT}$ & Lyn & 50 & $64(1943-2007)$ & $43580.4023 \pm 0.0032$ & $0.59743237 \pm 0.00000023$ & 0.0224 \\
\hline TW & Lyn & 70 & 48 (1956-2004) & $45022.4961 \pm 0.0022$ & $0.48186052 \pm 0.00000013$ & 0.0187 \\
\hline $\mathrm{CN}$ & Lyr & 72 & 105 (1901-2006) & $36079.3242 \pm 0.0018$ & $0.41138276 \pm 0.00000005$ & 0.0104 \\
\hline IO & Lyr & 95 & 97 (1909-2006) & $36276.2305 \pm 0.0013$ & $0.57712215 \pm 0.00000007$ & 0.0113 \\
\hline $\mathrm{KX}$ & Lyr & 62 & $65(1940-2005)$ & $42019.2461 \pm 0.0036$ & $0.44090429 \pm 0.00000017$ & 0.0188 \\
\hline LX & Lyr & 33 & 64 (1940-2004) & $36287.2930 \pm 0.0026$ & $0.54548401 \pm 0.00000022$ & 0.0148 \\
\hline RV & Oct & 140 & $91(1900-1991)$ & $31874.5703 \pm 0.0029$ & $0.57116264 \pm 0.00000022$ & 0.0347 \\
\hline ST & Oph & 29 & $98(1908-2006)$ & $36079.3438 \pm 0.0028$ & $0.45035613 \pm 0.00000011$ & 0.0144 \\
\hline V531 & Oph & 25 & $64(1928-1992)$ & $39618.5156 \pm 0.0033$ & $0.55365324 \pm 0.00000022$ & 0.0166 \\
\hline V2033 & Oph & 24 & $52(1940-1992)$ & $39270.5352 \pm 0.0047$ & $0.56582946 \pm 0.00000043$ & 0.0201 \\
\hline $\mathrm{AO}$ & Peg & 23 & $80(1925-2005)$ & $37909.3984 \pm 0.0021$ & $0.54724342 \pm 0.00000010$ & 0.0092 \\
\hline $\mathrm{BF}$ & Peg & 24 & 73 (1931-2004) & $39369.1758 \pm 0.0062$ & $0.49580538 \pm 0.00000029$ & 0.0301 \\
\hline CG & Peg & 109 & $51(1956-2007)$ & $45576.4414 \pm 0.0015$ & $0.46713728 \pm 0.00000010$ & 0.0144 \\
\hline DZ & Peg & 63 & 97 (1910-2007) & $36511.4062 \pm 0.0043$ & $0.60734892 \pm 0.00000026$ & 0.0313 \\
\hline VY & Ser & 41 & $74(1932-2006)$ & $39615.9297 \pm 0.0049$ & $0.71409613 \pm 0.00000038$ & 0.0225 \\
\hline AN & Ser & 106 & 107 (1899-2006) & $34265.2461 \pm 0.0014$ & $0.52207130 \pm 0.00000007$ & $0.0131^{B}$ \\
\hline DF & Ser & 42 & 105 (1900-2005) & $34195.6641 \pm 0.0019$ & $0.43779647 \pm 0.00000008$ & 0.0125 \\
\hline UU & Vir & 23 & $97(1903-2000)$ & $34509.2617 \pm 0.0012$ & $0.47560632 \pm 0.00000005$ & 0.0059 \\
\hline WY & Vir & 37 & $87(1914-2001)$ & $38060.6328 \pm 0.0068$ & $0.60935342 \pm 0.00000058$ & $0.0409^{B}$ \\
\hline AS & Vir & 19 & $84(1916-2000)$ & $37052.4844 \pm 0.0123$ & $0.55342495 \pm 0.00000075$ & 0.0407 \\
\hline AV & Vir & 25 & $93(1913-2006)$ & $37016.4492 \pm 0.0025$ & $0.65690929 \pm 0.00000012$ & 0.0097 \\
\hline
\end{tabular}


Table 4. Parabolic elements for RRab stars showing a well-defined linearly increasing period. The note ${ }^{B}$ beside the value of the standard deviation indicates the stars having a known Blazhko effect and discussed in the text.

\begin{tabular}{|c|c|c|c|c|c|c|c|c|c|}
\hline Star & $N_{\max }$ & $\begin{array}{l}\text { Time coverage } \\
\text { [years] }\end{array}$ & $\begin{array}{c}\text { Epoch } \\
\text { [HJD-2 } 400 \text { 000] }\end{array}$ & $\begin{array}{l}\text { Period } \\
\text { [d] }\end{array}$ & $\begin{array}{l}\text { Quad. term } \\
{\left[10^{-10} \cdot \mathrm{d}\right]}\end{array}$ & $\begin{array}{l}\text { s.d. } \\
{[d]}\end{array}$ & $\begin{array}{c}\mathrm{d} P / \mathrm{d} t \\
{\left[10^{-10} \cdot \mathrm{d} / \mathrm{d}\right]}\end{array}$ & $\begin{array}{c}\beta \\
{\left[\mathrm{d} \mathrm{Myr}^{-1}\right]}\end{array}$ & $\begin{array}{c}\alpha \\
{\left[\mathrm{Myr}^{-1}\right]}\end{array}$ \\
\hline $\mathrm{XX}$ And & 182 & $\begin{array}{c}105 \\
(1902-2007)\end{array}$ & $\begin{array}{r}54106.3508 \\
\pm 0.0027\end{array}$ & $\begin{array}{r}0.72276008 \\
\pm 0.00000029\end{array}$ & $\begin{array}{r}1.427 \\
\pm 0.066\end{array}$ & 0.0167 & $\begin{array}{r}3.95 \\
\pm 0.18\end{array}$ & $\begin{array}{r}0.144 \\
\pm 0.007\end{array}$ & $\begin{array}{r}0.200 \\
\pm 0.009\end{array}$ \\
\hline BN Aqr & 78 & $\begin{array}{c}110 \\
(1896-2006)\end{array}$ & $\begin{array}{r}53979.4964 \\
\pm 0.0049\end{array}$ & $\begin{array}{r}0.46967415 \\
\pm 0.00000026\end{array}$ & $\begin{array}{r}3.173 \\
\pm 0.030\end{array}$ & 0.0149 & $\begin{array}{l}13.51 \\
\pm 0.13\end{array}$ & $\begin{array}{r}0.494 \\
\pm 0.005\end{array}$ & $\begin{array}{r}1.051 \\
\pm 0.010\end{array}$ \\
\hline V341 Aql & 117 & $\begin{array}{c}94 \\
(1912-2006)\end{array}$ & $\begin{array}{r}53999.4346 \\
\pm 0.0025\end{array}$ & $\begin{array}{r}0.57802322 \\
\pm 0.00000027\end{array}$ & $\begin{array}{r}0.613 \\
\pm 0.056\end{array}$ & 0.0130 & $\begin{array}{r}2.12 \\
\pm 0.19\end{array}$ & $\begin{array}{r}0.078 \\
\pm 0.007\end{array}$ & $\begin{array}{r}0.134 \\
\pm 0.012\end{array}$ \\
\hline X Ari & 112 & $\begin{array}{c}93 \\
(1914-2007)\end{array}$ & $\begin{array}{r}54107.2779 \\
\pm 0.0021\end{array}$ & $\begin{array}{r}0.65116811 \\
\pm 0.00000028\end{array}$ & $\begin{array}{r}4.763 \\
\pm 0.060\end{array}$ & 0.0135 & $\begin{array}{r}14.63 \\
\pm 0.18\end{array}$ & $\begin{array}{r}0.535 \\
\pm 0.007\end{array}$ & $\begin{array}{r}0.821 \\
\pm 0.010\end{array}$ \\
\hline RS Boo & 325 & $\begin{array}{c}107 \\
(1900-2007)\end{array}$ & $\begin{array}{r}54113.6372 \\
\pm 0.0011\end{array}$ & $\begin{array}{r}0.37734035 \\
\pm 0.00000006\end{array}$ & $\begin{array}{r}0.268 \\
\pm 0.007\end{array}$ & $0.0093^{B}$ & $\begin{array}{r}1.42 \\
\pm 0.04\end{array}$ & $\begin{array}{r}0.052 \\
\pm 0.001\end{array}$ & $\begin{array}{r}0.137 \\
\pm 0.004\end{array}$ \\
\hline SW Boo & 52 & $\begin{array}{c}98 \\
(1908-2006)\end{array}$ & $\begin{array}{r}53919.4937 \\
\pm 0.0019\end{array}$ & $\begin{array}{r}0.51355094 \\
\pm 0.00000017\end{array}$ & $\begin{array}{r}4.639 \\
\pm 0.030\end{array}$ & $0.0080^{B}$ & $\begin{array}{l}18.07 \\
\pm 0.12\end{array}$ & $\begin{array}{r}0.660 \\
\pm 0.004\end{array}$ & $\begin{array}{r}1.286 \\
\pm 0.008\end{array}$ \\
\hline UU Boo & 88 & $\begin{array}{c}99 \\
(1907-2006)\end{array}$ & $\begin{array}{r}53904.4944 \\
\pm 0.0023\end{array}$ & $\begin{array}{r}0.45693375 \\
\pm 0.00000017\end{array}$ & $\begin{array}{r}2.231 \\
\pm 0.025\end{array}$ & 0.0116 & $\begin{array}{r}9.77 \\
\pm 0.11\end{array}$ & $\begin{array}{r}0.357 \\
\pm 0.004\end{array}$ & $\begin{array}{r}0.781 \\
\pm 0.009\end{array}$ \\
\hline RW Cnc & 95 & $\begin{array}{c}90 \\
(1916-2006)\end{array}$ & $\begin{array}{r}53746.5042 \\
\pm 0.0035\end{array}$ & $\begin{array}{r}0.54721602 \\
\pm 0.00000033\end{array}$ & $\begin{array}{r}1.937 \\
\pm 0.054\end{array}$ & 0.0169 & $\begin{array}{r}7.08 \\
\pm 0.20\end{array}$ & $\begin{array}{r}0.259 \\
\pm 0.007\end{array}$ & $\begin{array}{r}0.473 \\
\pm 0.013\end{array}$ \\
\hline TT Cnc & 97 & $\begin{array}{c}91 \\
(1916-2007)\end{array}$ & $\begin{array}{r}54112.4014 \\
\pm 0.0023\end{array}$ & $\begin{array}{r}0.56345656 \\
\pm 0.00000029\end{array}$ & $\begin{array}{r}1.229 \\
\pm 0.058\end{array}$ & $0.0132^{B}$ & $\begin{array}{r}4.36 \\
\pm 0.21\end{array}$ & $\begin{array}{r}0.159 \\
\pm 0.008\end{array}$ & $\begin{array}{r}0.283 \\
\pm 0.013\end{array}$ \\
\hline AN Cnc & 29 & $\begin{array}{c}96 \\
(1910-2006)\end{array}$ & $\begin{array}{r}53752.5259 \\
\pm 0.0043\end{array}$ & $\begin{array}{r}0.54316354 \\
\pm 0.00000037\end{array}$ & $\begin{array}{r}0.555 \\
\pm 0.067\end{array}$ & 0.0122 & $\begin{array}{r}2.04 \\
\pm 0.25\end{array}$ & $\begin{array}{r}0.075 \\
\pm 0.009\end{array}$ & $\begin{array}{r}0.137 \\
\pm 0.017\end{array}$ \\
\hline SW CVn & 19 & $\begin{array}{c}95 \\
(1910-2005)\end{array}$ & $\begin{array}{r}53478.5374 \\
\pm 0.0023\end{array}$ & $\begin{array}{r}0.44167101 \\
\pm 0.00000024\end{array}$ & $\begin{array}{r}2.033 \\
\pm 0.036\end{array}$ & 0.0066 & $\begin{array}{r}9.21 \\
\pm 0.16\end{array}$ & $\begin{array}{r}0.336 \\
\pm 0.006\end{array}$ & $\begin{array}{r}0.762 \\
\pm 0.013\end{array}$ \\
\hline EZ Cep & 89 & $\begin{array}{c}105 \\
(1901-2006)\end{array}$ & $\begin{array}{r}53750.3391 \\
\pm 0.0067\end{array}$ & $\begin{array}{r}0.37900204 \\
\pm 0.00000027\end{array}$ & $\begin{array}{r}0.296 \\
\pm 0.028\end{array}$ & 0.0236 & $\begin{array}{r}1.56 \\
\pm 0.15\end{array}$ & $\begin{array}{r}0.057 \\
\pm 0.005\end{array}$ & $\begin{array}{r}0.151 \\
\pm 0.014\end{array}$ \\
\hline RR Cet & 113 & $\begin{array}{c}100 \\
(1906-2006)\end{array}$ & $\begin{array}{r}54090.2963 \\
\pm 0.0014\end{array}$ & $\begin{array}{r}0.55302909 \\
\pm 0.00000011\end{array}$ & $\begin{array}{r}0.231 \\
\pm 0.020\end{array}$ & 0.0075 & $\begin{array}{r}0.84 \\
\pm 0.07\end{array}$ & $\begin{array}{r}0.031 \\
\pm 0.003\end{array}$ & $\begin{array}{r}0.055 \\
\pm 0.005\end{array}$ \\
\hline TV CrB & 124 & $\begin{array}{c}104 \\
(1902-2006)\end{array}$ & $\begin{array}{r}53903.4827 \\
\pm 0.0069\end{array}$ & $\begin{array}{r}0.58461776 \\
\pm 0.00000047\end{array}$ & $\begin{array}{r}0.893 \\
\pm 0.074\end{array}$ & 0.0311 & $\begin{array}{r}3.06 \\
\pm 0.25\end{array}$ & $\begin{array}{r}0.112 \\
\pm 0.009\end{array}$ & $\begin{array}{r}0.191 \\
\pm 0.016\end{array}$ \\
\hline DM Cyg & 223 & $\begin{array}{c}106 \\
(1900-2006)\end{array}$ & $\begin{array}{r}54035.4065 \\
\pm 0.0009\end{array}$ & $\begin{array}{r}0.41986367 \\
\pm 0.00000007\end{array}$ & $\begin{array}{r}0.523 \\
\pm 0.010\end{array}$ & $0.0066^{B}$ & $\begin{array}{r}2.49 \\
\pm 0.05\end{array}$ & $\begin{array}{r}0.091 \\
\pm 0.002\end{array}$ & $\begin{array}{r}0.217 \\
\pm 0.004\end{array}$ \\
\hline V684 Cyg & 36 & $\begin{array}{c}53 \\
(1927-1980)\end{array}$ & $\begin{array}{r}44253.2522 \\
\pm 0.0084\end{array}$ & $\begin{array}{r}0.54099474 \\
\pm 0.00000119\end{array}$ & $\begin{array}{r}5.222 \\
\pm 0.314\end{array}$ & 0.0227 & $\begin{array}{r}19.30 \\
\pm 1.16\end{array}$ & $\begin{array}{r}0.705 \\
\pm 0.042\end{array}$ & $\begin{array}{r}1.304 \\
\pm 0.079\end{array}$ \\
\hline SU Dra & 189 & $\begin{array}{c}103 \\
(1904-2007)\end{array}$ & $\begin{array}{r}54111.5136 \\
\pm 0.0020\end{array}$ & $\begin{array}{r}0.66042294 \\
\pm 0.00000019\end{array}$ & $\begin{array}{r}0.561 \\
\pm 0.034\end{array}$ & 0.0124 & $\begin{array}{r}1.70 \\
\pm 0.10\end{array}$ & $\begin{array}{r}0.062 \\
\pm 0.004\end{array}$ & $\begin{array}{r}0.094 \\
\pm 0.006\end{array}$ \\
\hline SV Eri & 54 & $\begin{array}{c}104 \\
(1904-2006)\end{array}$ & $\begin{array}{r}53998.8128 \\
\pm 0.0153\end{array}$ & $\begin{array}{r}0.71387846 \\
\pm 0.00000142\end{array}$ & $\begin{array}{r}20.72 \\
\pm 0.304\end{array}$ & 0.0429 & $\begin{array}{l}58.06 \\
\pm 0.85\end{array}$ & $\begin{array}{r}2.121 \\
\pm 0.031\end{array}$ & $\begin{array}{r}2.972 \\
\pm 0.044\end{array}$ \\
\hline VZ Her & 203 & $\begin{array}{c}107 \\
(1899-2006)\end{array}$ & $\begin{array}{r}53967.4819 \\
\pm 0.0031\end{array}$ & $\begin{array}{r}0.44033227 \\
\pm 0.00000018\end{array}$ & $\begin{array}{r}0.678 \\
\pm 0.023\end{array}$ & 0.0207 & $\begin{array}{r}3.08 \\
\pm 0.10\end{array}$ & $\begin{array}{r}0.112 \\
\pm 0.004\end{array}$ & $\begin{array}{r}0.255 \\
\pm 0.009\end{array}$ \\
\hline RR Leo & 298 & $\begin{array}{c}109 \\
(1898-2007)\end{array}$ & $\begin{array}{r}54124.4177 \\
\pm 0.0009\end{array}$ & $\begin{array}{r}0.45240129 \\
\pm 0.00000006\end{array}$ & $\begin{array}{r}1.869 \\
\pm 0.009\end{array}$ & 0.0072 & $\begin{array}{r}8.26 \\
\pm 0.04\end{array}$ & $\begin{array}{r}0.302 \\
\pm 0.001\end{array}$ & $\begin{array}{r}0.668 \\
\pm 0.003\end{array}$ \\
\hline TV Leo & 27 & $\begin{array}{c}89 \\
(1913-2002)\end{array}$ & $\begin{array}{r}52373.1085 \\
\pm 0.0184\end{array}$ & $\begin{array}{r}0.67286445 \\
\pm 0.00000147\end{array}$ & $\begin{array}{r}3.271 \\
\pm 0.284\end{array}$ & 0.0307 & $\begin{array}{r}9.72 \\
\pm 0.84\end{array}$ & $\begin{array}{r}0.355 \\
\pm 0.031\end{array}$ & $\begin{array}{r}0.528 \\
\pm 0.046\end{array}$ \\
\hline U Lep & 33 & $\begin{array}{c}118 \\
(1899-2007)\end{array}$ & $\begin{array}{r}54114.6303 \\
\pm 0.0019\end{array}$ & $\begin{array}{r}0.58147954 \\
\pm 0.00000018\end{array}$ & $\begin{array}{r}0.685 \\
\pm 0.030\end{array}$ & 0.0077 & $\begin{array}{r}2.36 \\
\pm 0.10\end{array}$ & $\begin{array}{r}0.086 \\
\pm 0.004\end{array}$ & $\begin{array}{r}0.148 \\
\pm 0.006\end{array}$ \\
\hline AV Peg & 443 & $\begin{array}{c}103 \\
(1903-2006)\end{array}$ & $\begin{array}{r}54060.3926 \\
\pm 0.0010\end{array}$ & $\begin{array}{r}0.39038092 \\
\pm 0.00000006\end{array}$ & $\begin{array}{r}0.894 \\
\pm 0.010\end{array}$ & 0.0084 & $\begin{array}{r}4.58 \\
\pm 0.05\end{array}$ & $\begin{array}{r}0.167 \\
\pm 0.002\end{array}$ & $\begin{array}{r}0.429 \\
\pm 0.005\end{array}$ \\
\hline AR Per & 153 & $\begin{array}{c}107 \\
(1900-2007)\end{array}$ & $\begin{array}{r}54124.4299 \\
\pm 0.0008\end{array}$ & $\begin{array}{r}0.42555066 \\
\pm 0.00000006\end{array}$ & $\begin{array}{r}0.136 \\
\pm 0.009\end{array}$ & 0.0057 & $\begin{array}{r}0.64 \\
\pm 0.04\end{array}$ & $\begin{array}{r}0.023 \\
\pm 0.001\end{array}$ & $\begin{array}{r}0.055 \\
\pm 0.003\end{array}$ \\
\hline RY Psc & 42 & $\begin{array}{c}96 \\
(1912-2006)\end{array}$ & $\begin{array}{r}54037.5428 \\
\pm 0.0086\end{array}$ & $\begin{array}{r}0.52973431 \\
\pm 0.00000062\end{array}$ & $\begin{array}{r}0.863 \\
\pm 0.098\end{array}$ & 0.0205 & $\begin{array}{r}3.26 \\
\pm 0.37\end{array}$ & $\begin{array}{r}0.119 \\
\pm 0.014\end{array}$ & $\begin{array}{r}0.225 \\
\pm 0.026\end{array}$ \\
\hline CS Ser & 27 & $\begin{array}{c}102 \\
(1903-2005)\end{array}$ & $\begin{array}{r}53530.4879 \\
\pm 0.0090\end{array}$ & $\begin{array}{r}0.52679833 \\
\pm 0.00000050\end{array}$ & $\begin{array}{r}0.747 \\
\pm 0.066\end{array}$ & 0.0142 & $\begin{array}{r}2.84 \\
\pm 0.25\end{array}$ & $\begin{array}{r}0.104 \\
\pm 0.009\end{array}$ & $\begin{array}{r}0.197 \\
\pm 0.017\end{array}$ \\
\hline BB Vir & 25 & $\begin{array}{c}94 \\
(1903-2005)\end{array}$ & $\begin{array}{r}53849.6121 \\
\pm 0.0062\end{array}$ & $\begin{array}{r}0.47110683 \\
\pm 0.00000060\end{array}$ & $\begin{array}{r}1.083 \\
\pm 0.089\end{array}$ & 0.0193 & $\begin{array}{r}4.60 \\
\pm 0.38\end{array}$ & $\begin{array}{r}0.168 \\
\pm 0.014\end{array}$ & $\begin{array}{r}0.357 \\
\pm 0.029\end{array}$ \\
\hline
\end{tabular}


J. F. Le Borgne et al.: Period changes in RR Lyr stars, Online Material p 4

Table 5. Parabolic elements for RRab stars showing a well-defined linearly decreasing period. The note ${ }^{B}$ beside the value of the standard deviation indicates the stars having a known Blazhko effect and discussed in the text.

\begin{tabular}{|c|c|c|c|c|c|c|c|c|c|}
\hline Star & $N_{\max }$ & $\begin{array}{c}\text { Time coverage } \\
\text { [years] }\end{array}$ & $\begin{array}{c}\text { Epoch } \\
\text { [HJD-2 } 400000]\end{array}$ & $\begin{array}{l}\text { Period } \\
\text { [d] }\end{array}$ & $\begin{array}{l}\text { Quad. term } \\
{\left[10^{-10} \cdot d / d\right]}\end{array}$ & $\begin{array}{l}\text { s.d. } \\
{[\mathrm{d}]}\end{array}$ & $\begin{array}{c}\mathrm{d} P / \mathrm{d} t \\
{\left[10^{-10} \cdot \mathrm{d} / \mathrm{d}\right]}\end{array}$ & $\begin{array}{c}\beta \\
{\left[\mathrm{d} \mathrm{Myr}^{-1}\right]}\end{array}$ & $\begin{array}{c}\alpha \\
{\left[\mathrm{Myr}^{-1}\right]}\end{array}$ \\
\hline SW And & 393 & $\begin{array}{c}111 \\
(1894-2005)\end{array}$ & $\begin{array}{r}54093.3336 \\
\pm 0.0016\end{array}$ & $\begin{array}{r}0.44226187 \\
\pm 0.00000010\end{array}$ & $\begin{array}{l}-1.013 \\
\pm 0.013\end{array}$ & $0.0132^{B}$ & $\begin{array}{l}-4.58 \\
\pm 0.06\end{array}$ & $\begin{array}{l}-0.167 \\
\pm 0.002\end{array}$ & $\begin{array}{l}-0.378 \\
\pm 0.005\end{array}$ \\
\hline SX Aqr & 97 & $\begin{array}{c}93 \\
(1913-2006)\end{array}$ & $\begin{array}{r}54018.3651 \\
\pm 0.0031\end{array}$ & $\begin{array}{r}0.53570932 \\
\pm 0.00000025\end{array}$ & $\begin{array}{l}-0.537 \\
\pm 0.040\end{array}$ & 0.0139 & $\begin{array}{l}-2.00 \\
\pm 0.15\end{array}$ & $\begin{array}{l}-0.073 \\
\pm 0.005\end{array}$ & $\begin{array}{l}-0.137 \\
\pm 0.010\end{array}$ \\
\hline BR Aqr & 66 & $\begin{array}{c}105 \\
(1901-2006)\end{array}$ & $\begin{array}{r}54048.3622 \\
\pm 0.0045\end{array}$ & $\begin{array}{r}0.48187046 \\
\pm 0.00000024\end{array}$ & $\begin{array}{l}-0.950 \\
\pm 0.031\end{array}$ & 0.0128 & $\begin{array}{l}-3.94 \\
\pm 0.13\end{array}$ & $\begin{array}{l}-0.144 \\
\pm 0.005\end{array}$ & $\begin{array}{l}-0.299 \\
\pm 0.010\end{array}$ \\
\hline CP Aqr & 82 & $\begin{array}{c}72 \\
(1912-2006)\end{array}$ & $\begin{array}{r}54024.3267 \\
\pm 0.0025\end{array}$ & $\begin{array}{r}0.46340227 \\
\pm 0.00000017\end{array}$ & $\begin{array}{l}-0.516 \\
\pm 0.030\end{array}$ & 0.0103 & $\begin{array}{l}-2.23 \\
\pm 0.13\end{array}$ & $\begin{array}{l}-0.081 \\
\pm 0.005\end{array}$ & $\begin{array}{l}-0.176 \\
\pm 0.010\end{array}$ \\
\hline TW Boo & 92 & $\begin{array}{c}92 \\
(1914-2006)\end{array}$ & $\begin{array}{r}53918.4570 \\
\pm 0.0015\end{array}$ & $\begin{array}{r}0.53226977 \\
\pm 0.00000019\end{array}$ & $\begin{array}{l}-0.503 \\
\pm 0.036\end{array}$ & 0.0095 & $\begin{array}{l}-1.89 \\
\pm 0.14\end{array}$ & $\begin{array}{l}-0.069 \\
\pm 0.005\end{array}$ & $\begin{array}{l}-0.130 \\
\pm 0.009\end{array}$ \\
\hline AH Cam & 109 & $\begin{array}{c}56 \\
(1951-2007)\end{array}$ & $\begin{array}{r}54119.3136 \\
\pm 0.0029\end{array}$ & $\begin{array}{r}0.36871531 \\
\pm 0.00000039\end{array}$ & $\begin{array}{l}-2.397 \\
\pm 0.076\end{array}$ & $0.0167^{B}$ & $\begin{array}{r}-13.00 \\
\pm 0.41\end{array}$ & $\begin{array}{l}-0.475 \\
\pm 0.015\end{array}$ & $\begin{array}{l}-1.288 \\
\pm 0.041\end{array}$ \\
\hline $\mathrm{AP} \mathrm{Cnc}$ & 24 & $\begin{array}{c}72 \\
(1930-2002)\end{array}$ & $\begin{array}{r}52635.7481 \\
\pm 0.0192\end{array}$ & $\begin{array}{r}0.53293273 \\
\pm 0.00000138\end{array}$ & $\begin{array}{l}-2.178 \\
\pm 0.249\end{array}$ & 0.0259 & $\begin{array}{l}-8.17 \\
\pm 0.93\end{array}$ & $\begin{array}{l}-0.299 \\
\pm 0.034\end{array}$ & $\begin{array}{l}-0.560 \\
\pm 0.064\end{array}$ \\
\hline W CVn & 110 & $\begin{array}{c}105 \\
(1902-2006)\end{array}$ & $\begin{array}{r}54121.6211 \\
\pm 0.0012\end{array}$ & $\begin{array}{r}0.55175472 \\
\pm 0.00000014\end{array}$ & $\begin{array}{l}-0.412 \\
\pm 0.024\end{array}$ & 0.0073 & $\begin{array}{l}-1.49 \\
\pm 0.09\end{array}$ & $\begin{array}{l}-0.055 \\
\pm 0.003\end{array}$ & $\begin{array}{l}-0.099 \\
\pm 0.006\end{array}$ \\
\hline RV Cap & 258 & $\begin{array}{c}95 \\
(1906-2001)\end{array}$ & $\begin{array}{r}51982.7919 \\
\pm 0.0144\end{array}$ & $\begin{array}{r}0.44773748 \\
\pm 0.00000069\end{array}$ & $\begin{array}{l}-1.260 \\
\pm 0.084\end{array}$ & $0.0270^{B}$ & $\begin{array}{l}-5.63 \\
\pm 0.37\end{array}$ & $\begin{array}{l}-0.206 \\
\pm 0.014\end{array}$ & $\begin{array}{l}-0.459 \\
\pm 0.030\end{array}$ \\
\hline RX Cet & 120 & $\begin{array}{c}111 \\
(1890-2001)\end{array}$ & $\begin{array}{r}52172.1923 \\
\pm 0.0128\end{array}$ & $\begin{array}{r}0.57368560 \\
\pm 0.00000061\end{array}$ & $\begin{array}{l}-1.950 \\
\pm 0.075\end{array}$ & 0.0280 & $\begin{array}{l}-6.80 \\
\pm 0.26\end{array}$ & $\begin{array}{l}-0.248 \\
\pm 0.010\end{array}$ & $\begin{array}{l}-0.433 \\
\pm 0.017\end{array}$ \\
\hline RZ Cet & 39 & $\begin{array}{c}77 \\
(1929-2006)\end{array}$ & $\begin{array}{r}54036.5318 \\
\pm 0.0133\end{array}$ & $\begin{array}{r}0.51059118 \\
\pm 0.00000127\end{array}$ & $\begin{array}{l}-4.032 \\
\pm 0.224\end{array}$ & 0.0336 & $\begin{array}{r}-15.79 \\
\pm 0.88\end{array}$ & $\begin{array}{r}-0.577 \\
\pm 0.032\end{array}$ & $\begin{array}{l}-1.130 \\
\pm 0.063\end{array}$ \\
\hline S Com & 89 & $\begin{array}{c}96 \\
(1911-2007)\end{array}$ & $\begin{array}{r}54118.5568 \\
\pm 0.0019\end{array}$ & $\begin{array}{r}0.58658461 \\
\pm 0.00000018\end{array}$ & $\begin{array}{l}-0.773 \\
\pm 0.032\end{array}$ & 0.0097 & $\begin{array}{l}-2.64 \\
\pm 0.11\end{array}$ & $\begin{array}{l}-0.096 \\
\pm 0.004\end{array}$ & $\begin{array}{l}-0.164 \\
\pm 0.007\end{array}$ \\
\hline VX Her & 164 & $\begin{array}{c}90 \\
(1916-2006)\end{array}$ & $\begin{array}{r}53919.4514 \\
\pm 0.0016\end{array}$ & $\begin{array}{r}0.45536088 \\
\pm 0.00000013\end{array}$ & $\begin{array}{l}-0.922 \\
\pm 0.022\end{array}$ & 0.0107 & $\begin{array}{l}-4.05 \\
\pm 0.09\end{array}$ & $\begin{array}{l}-0.148 \\
\pm 0.003\end{array}$ & $\begin{array}{l}-0.325 \\
\pm 0.008\end{array}$ \\
\hline V394 Her & 105 & $\begin{array}{c}77 \\
(1929-2001)\end{array}$ & $\begin{array}{r}53932.4381 \\
\pm 0.0049\end{array}$ & $\begin{array}{r}0.43605116 \\
\pm 0.00000042\end{array}$ & $\begin{array}{l}-0.748 \\
\pm 0.070\end{array}$ & 0.0205 & $\begin{array}{l}-3.43 \\
\pm 0.32\end{array}$ & $\begin{array}{l}-0.125 \\
\pm 0.012\end{array}$ & $\begin{array}{l}-0.287 \\
\pm 0.027\end{array}$ \\
\hline RZ Lyr & 396 & $\begin{array}{c}111 \\
(1895-2006)\end{array}$ & $\begin{array}{r}53983.3800 \\
\pm 0.0024\end{array}$ & $\begin{array}{r}0.51123785 \\
\pm 0.00000014\end{array}$ & $\begin{array}{l}-1.312 \\
\pm 0.019\end{array}$ & $0.0172^{B}$ & $\begin{array}{l}-5.13 \\
\pm 0.08\end{array}$ & $\begin{array}{l}-0.188 \\
\pm 0.005\end{array}$ & $\begin{array}{l}-0.367 \\
\pm 0.003\end{array}$ \\
\hline V1095 Oph & 32 & $\begin{array}{c}64 \\
(1928-1992)\end{array}$ & $\begin{array}{r}48832.4223 \\
\pm 0.0074\end{array}$ & $\begin{array}{r}0.45877735 \\
\pm 0.00000091\end{array}$ & $\begin{array}{l}-1.246 \\
\pm 0.174\end{array}$ & 0.0212 & $\begin{array}{l}-5.43 \\
\pm 0.76\end{array}$ & $\begin{array}{l}-0.198 \\
\pm 0.028\end{array}$ & $\begin{array}{l}-0.433 \\
\pm 0.060\end{array}$ \\
\hline V964 Ori & 24 & $\begin{array}{c}104 \\
(1902-2006)\end{array}$ & $\begin{array}{r}54080.5994 \\
\pm 0.0045\end{array}$ & $\begin{array}{r}0.50463562 \\
\pm 0.00000028\end{array}$ & $\begin{array}{l}-2.730 \\
\pm 0.039\end{array}$ & 0.0087 & $\begin{array}{r}-10.82 \\
\pm 0.15\end{array}$ & $\begin{array}{l}-0.395 \\
\pm 0.006\end{array}$ & $\begin{array}{l}-0.783 \\
\pm 0.011\end{array}$ \\
\hline BH Peg & 131 & $\begin{array}{c}73 \\
(1932-2006)\end{array}$ & $\begin{array}{r}54059.2925 \\
\pm 0.0028\end{array}$ & $\begin{array}{r}0.64098176 \\
\pm 0.00000035\end{array}$ & $\begin{array}{l}-2.785 \\
\pm 0.084\end{array}$ & $0.0168^{B}$ & $\begin{array}{l}-8.69 \\
\pm 0.26\end{array}$ & $\begin{array}{l}-0.317 \\
\pm 0.010\end{array}$ & $\begin{array}{l}-0.495 \\
\pm 0.015\end{array}$ \\
\hline SW Psc & 30 & $\begin{array}{c}54 \\
(1912-1966)\end{array}$ & $\begin{array}{r}39410.3459 \\
\pm 0.0079\end{array}$ & $\begin{array}{r}0.52124757 \\
\pm 0.00000152\end{array}$ & $\begin{array}{l}-5.395 \\
\pm 0.433\end{array}$ & $0.0272^{B}$ & $\begin{array}{r}-20.70 \\
\pm 1.66\end{array}$ & $\begin{array}{l}-0.756 \\
\pm 0.061\end{array}$ & $\begin{array}{l}-1.451 \\
\pm 0.116\end{array}$ \\
\hline HK Pup & 38 & $\begin{array}{c}76 \\
(1930-2006)\end{array}$ & $\begin{array}{r}54100.6304 \\
\pm 0.0161\end{array}$ & $\begin{array}{r}0.73421141 \\
\pm 0.00000165\end{array}$ & $\begin{array}{l}-7.216 \\
\pm 0.412\end{array}$ & 0.0285 & $\begin{array}{r}-19.66 \\
\pm 1.12\end{array}$ & $\begin{array}{l}-0.718 \\
\pm 0.041\end{array}$ & $\begin{array}{l}-0.978 \\
\pm 0.056\end{array}$ \\
\hline AT Vir & 25 & $\begin{array}{c}89 \\
(1915-2004) \\
\end{array}$ & $\begin{array}{r}53487.4580 \\
\pm 0.0049 \\
\end{array}$ & $\begin{array}{r}0.52577511 \\
\pm 0.00000047 \\
\end{array}$ & $\begin{array}{l}-3.350 \\
\pm 0.086 \\
\end{array}$ & 0.0140 & $\begin{array}{r}-12.74 \\
\pm 0.33 \\
\end{array}$ & $\begin{array}{l}-0.466 \\
\pm 0.012 \\
\end{array}$ & $\begin{array}{l}-0.885 \\
\pm 0.023 \\
\end{array}$ \\
\hline
\end{tabular}


J. F. Le Borgne et al.: Period changes in RR Lyr stars, Online Material p 5
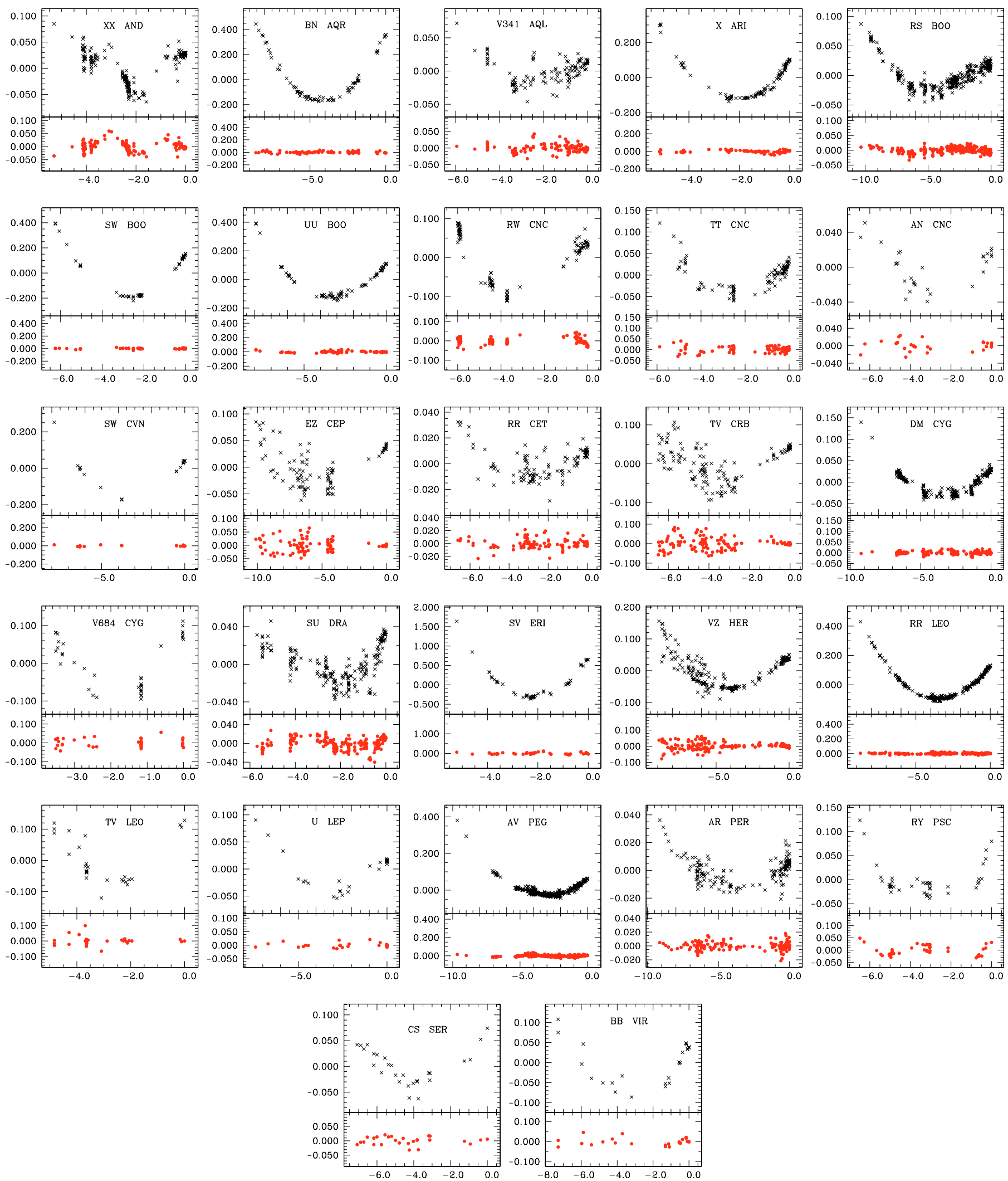

Fig. 2. O-C values for RRab stars. Filled circles indicate $\mathrm{O}-\mathrm{C}$ values calculated from the parabolic fit (period increasing at a constant rate), crosses from the linear fit (constant period). On the $x$-axis we plot the elapsed cycles (E/10000); on the ordinate one we plot the $\mathrm{O}-\mathrm{C}$ values in days. The cases of V341 Aql, RS Boo, RW Cnc, EZ Cep and SU Dra are discussed in the text. 
J. F. Le Borgne et al.: Period changes in RR Lyr stars, Online Material p 6
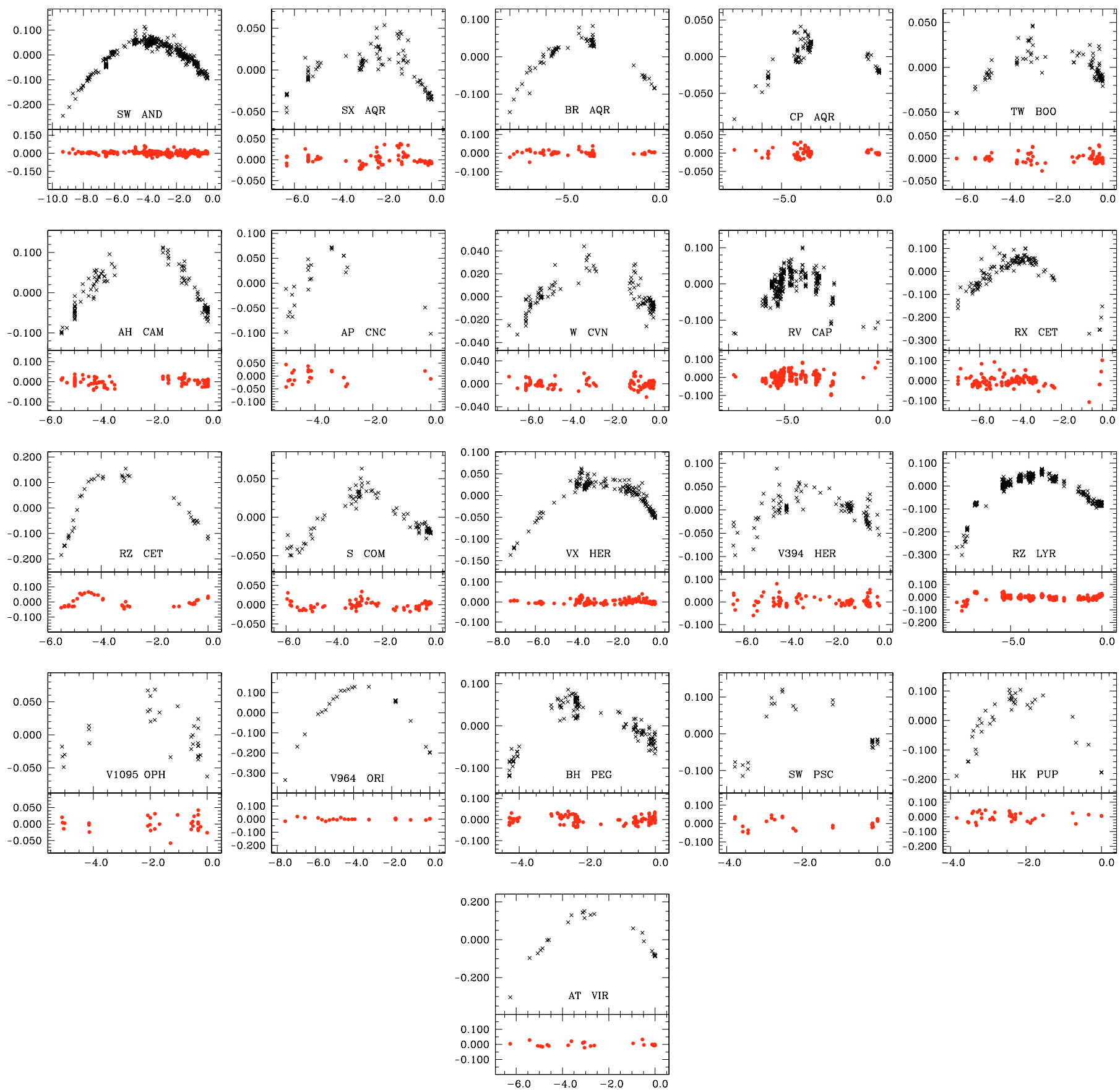

Fig. 3. $\mathrm{O}-\mathrm{C}$ values for RRab stars. Filled circles indicate $\mathrm{O}-\mathrm{C}$ values calculated from the parabolic fit (period decreasing at a constant rate), crosses from the linear fit (constant period). On the $x$-axis we plot the elapsed cycles (E/10000); on the ordinates the $\mathrm{O}-\mathrm{C}$ values are in days. 